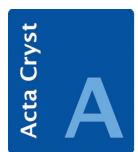

FOUNDATIONS ADVANCES
Keywords: International Union of Crystallography; IUCr; Executive Committee.

Supporting information: this article has supporting information at journals.iucr.org/a

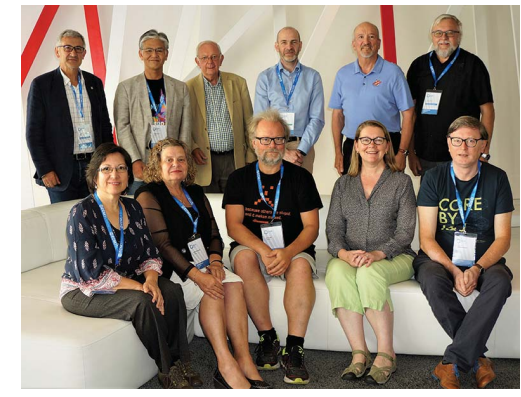

C 2020 International Union of Crystallography

\section{Report of the Executive Committee for 2019}

\section{Meetings}

The IUCr sponsored the following meetings held during 2019:

5th Conference of the Bangladesh Crystallographic Association, Dhaka, Bangladesh, 25-26 January 2019;

2nd PAN African Meeting on Crystallography, Accra, Ghana, 28 January - 2 February 2019 ;

5th School on Crystal Structure Determination from Diffraction Data. Application on Powder Samples, Hammamet, Tunisia, 22-24 March 2019;

XVII Intensive Teaching School in X-ray Structure Analysis, Durham, UK, 6-14 April 2019;

7th International School on Biological Crystallization, Granada, Spain, 26-31 May 2019;

To.Sca.Lake 3.0 Total Scattering for Nanotechnology on the Como Lake, Como, Italy, 27-31 May 2019;

2019 Magnetic Crystallography Course of the International School of Crystallography, Erice, Italy, 31 May - 9 June 2019;

14th International Symposium on Macrocyclic and Supramolecular Chemistry (ISMSC 2019), Lecce, Italy, 2-6 June 2019;

Summer School on Mathematical Crystallography, Nancy, France, 3-7 June 2019;

24th International Conference on the Chemistry of the Organic Solid State (ICCOSS

XXIV), New York City, New York, USA, 16-21 June 2019;

Zurich School of Crystallography 2019 - Bring Your Own Crystals (8th School),

Zurich, Switzerland, 16-27 June 2019;

International School on Advanced Porous Materials, Como, Italy, 17-21 June 2019;

2019 Gordon Research Seminar - Crystal Growth and Assembly, Biddeford, Maine,

USA, 22-23 June 2019;

IXS2019 11th International Conference on Inelastic X-ray Scattering, Stony Brook, New York, USA, 23-28 June 2019;

Shanghai International School on Crystallographic Groups and Representations, and their Applications in Magnetic Structure Descriptions and Topological Insulator Studies, Shanghai, China, 30 June - 7 July 2019;

XIX International Meeting on Crystal Chemistry, X-ray Diffraction and Spectroscopy of Minerals, Apatity, Kola Peninsula, Russia, 2-5 July 2019;

Annual Meeting of the American Crystallographic Association (ACA 2019), Covington, Kentucky, USA, 20-24 July 2019;

The 17th International Summer School on Crystal Growth, Granby, Colorado, USA, 21-26 July 2019;

19th International Conference on Crystal Growth and Epitaxy (Crystal Growth 2019), Keystone, Colorado, 28 July - 2 August 2019;

Satellite Meeting of the 32nd European Crystallographic Meeting - High Pressure Crystallography Workshop, Vienna, Austria, 13-17 August 2019;

Satellite Meeting of the 32nd European Crystallographic Meeting - Mathematical and Theoretical Crystallographic Workshop, Vienna, Austria, 16-18 August 2019;

32nd European Crystallographic Meeting (ECM32 Vienna), Vienna, Austria, 18-23 August 2019;

AICS2019 - Crystallographic Information Fiesta, Naples, Italy, 30 August - 3 September 2019; 
ECSSC 17: 17th European Conference on Solid State Chemistry, Lille, France, 1-4 September 2019;

Fourth International School on Aperiodic Crystals, Cabourg, France, 9-13 September 2019;

Biophysical Approaches to Macromolecules and Cells: Integrated Tools for Life Sciences and Medicine, Nairobi, Kenya (moved to Arusha, Tanzania), 9-20 September 2019;

EXPO\&more International Workshop, Bari, Italy, 30 September - 3 October 2019;

Hot Topics in Contemporary Crystallography 4, Mlini, Dubrovnik, Croatia, 1-6 October 2019;

II LACA School 2019: Crystal Structure Determination by Powder and Single Crystal X-ray Diffraction, Bucaramanga, Colombia, 1-6 October 2019;

IV Meeting of the Latin American Crystallographic Association, Bucaramanga, Colombia, 7-10 October 2019;

XI School of Asociación Argentina de Cristalografía, San Carlos de Bariloche, Argentina, 18-22 November 2019;

16th Conference of the Asian Crystallographic Association, Singapore, 17-20 December 2019.

The Executive Committee met in Covington, Kentucky, USA, in July. The Finance Committee met in Leuven, Belgium, in March and in Covington, Kentucky, USA, in July, to prepare its advice and recommendations on finances, establishment and staff matters.

The most important items of business dealt with by the Executive Committee at its meetings, and in e-mail ballots, were:

editorial policy, pricing policy and subscription rates, approval of appointments of Editors and Co-editors, progress of IUCrJ, journals development, Journals Management Board meeting, special issues, Plan S and open access, and other matters concerning the IUCr journals;

review of contract with Wiley for the IUCr journals;

approval of audited accounts for the previous year;

status of membership subscriptions;

investment policy;

sponsorship and financial support for meetings, young scientists' support, Visiting Professorship Scheme, gender balance of programmes;

progress with Volumes A, A1, B, C, D, E, F, G, H and I of International Tables and development of associated software;

IUCr Newsletter;

World Database of Crystallographers;

Online Dictionary of Crystallography; and

promotional activities.

Other items dealt with in this way were:

consideration of publications, jointly with Oxford Univer-

sity Press, in the IUCr/OUP Book Series;

outreach and education, LAAAMP;

Crystallography in Africa;

review of activities of Commissions, formation of a new

Commission;

provision of services to and review of activities of Regional

Associates;

review of reports of IUCr Representatives on other bodies; updates on the Ewald and Bragg Prizes;

updates from the Committee on Gender Equity and

Diversity;

arrangements for the Prague Congress; and

Swiss registration and taxation.

Items concerning the Chester office were:

staffing requirements in the IUCr office in Chester;

office premises;

risk analysis; and

office technology.

\section{Publications}

Volume 75 of Acta Crystallographica, Volume 52 of Journal of Applied Crystallography (JAC), Volume 27 of Journal of Synchrotron Radiation (JSR), Volume 6 of IUCrJ and Volume 4 of IUCrData were published.

\section{Adhering Bodies}

A list of Adhering Bodies of the Union, with names and addresses of the Secretaries of the National Committees for Crystallography, was published as Appendix D to the Report of the Twenty-Fourth General Assembly and International Congress of Crystallography [Acta Cryst. (2020), A76, 217224].

\section{Work of the Commissions}

\subsection{Commission on Journals}

IUCr Journals continued to perform well during 2019, despite the ever-changing situation for all scientific archival journal publications. Through 2019 and ongoing in 2020, the efforts of Editors, reviewers and authors to increase the quality and impact of all the journals in a progressive, sustainable way continues to be a major focus and this is much appreciated. In this connection, three Commissioning Editors have been appointed to work across the journals with all of the Editorial Boards in commissioning articles and special issues: Roberto Steiner (Biology), Elena Boldyreva (Chemical Sciences) and (appointment confirmed in early 2020) Thomas Proffen (Materials, Methods and Instrumentation). It remains evident that the impact factor of an individual journal can spike for a couple of years owing to a single highly cited article. We welcome the fact that this indicates the IUCr journal to be the appropriate place of record for seminal contributions of high impact to the crystallography research community. Generally, such an article remains highly cited, itself, long after the paper has dropped out of the publication time range contributing to the journal's current impact factor.

Also, during 2019 and continuing into 2020, the Editor-inchief has been working with the existing Main Editors to appoint new Editors (both Main Editors and Co-editors) to increase the scope and outreach of the journals, especially in major growth areas, and also to increase the geographical and gender diversity of the Editorial Boards. This will be crucial 
international union of crystallography

Table 1

Statistics for IUCr Journals.

\begin{tabular}{|c|c|c|c|c|c|c|}
\hline & 2014 & 2015 & 2016 & 2017 & 2018 & 2019 \\
\hline \multirow{2}{*}{$\begin{array}{l}\text { No. of submissions (all) } \\
\text { without Acta E or IUCrData }\end{array}$} & 3814 & 3278 & 2231 & 2685 & 2678 & 2424 \\
\hline & 2336 & 2006 & 1689 & 1694 & 1880 & 1732 \\
\hline \multirow{2}{*}{$\begin{array}{l}\text { No. of published papers (all) } \\
\text { without Acta E or IUCrData }\end{array}$} & 2925 & 2557 & 2065 & 1880 & 1793 & 1710 \\
\hline & 1589 & 1390 & 1139 & 1047 & 1139 & 1153 \\
\hline \multirow{2}{*}{$\begin{array}{l}\text { No. of pages (all) } \\
\quad \text { without Acta E or IUCrData }\end{array}$} & 14408 & 13867 & 12451 & 11565 & 12473 & 12854 \\
\hline & 12057 & 10936 & 9181 & 8564 & 9856 & 10443 \\
\hline
\end{tabular}

for the journals over the next few years as they transition to an era of much increased open access and associated publishing paradigms.

Information on article publication is given in Table 1 . The total number of articles published in the journals in 2019 was 1710, which compares with 1793 in 2018 and 1880 in 2017. The overall rejection and withdrawal rate $(32 \%)$ was $5 \%$ higher than in 2018 (27\%). The number of open-access articles published in IUCr Journals in 2019 was 911, compared with 999 in 2018. The proportion of open-access articles published in our hybrid transformative journals in 2019 was 26\% (compared with $25 \%$ in 2018).

Andrew Allen, Editor-in-chief

\subsubsection{IUCrJ}

$I U C r J$ had another good year in 2019 , with a record number of articles and pages published. It has continued to establish itself within the wider scientific communities that use results obtained from diffraction methods, and impressions from authors, readers, referees and commentators remain positive.

The impact factor announced for IUCrJ in 2019 was 4.8. All submissions undergo preliminary screening by a panel consisting of the Main Editors (Dimitri Argyriou, Ted Baker, Richard Catlow, Gautam Desiraju, John Spence and Sriram Subramaniam) and the Editor-in-chief (Andrew Allen), and this has helped to provide a rapid and efficient review process. Articles that do not meet the journal's requirement for broad scientific significance are often transferred, with the agreement of the authors, to another IUCr journal. Such transfers are seamless and do not require any further work by the authors.

The six issues of $I U C r J$ published in 2019 have featured papers from a wide variety of areas including biology, chemistry, crystal engineering, cryo-EM, materials, physics and FELs. The number of articles submitted to the journal was 147; a total of 120 papers were published with an average turnaround time of 16 weeks. Articles have been publicized in IUCrJ's social media feeds and by other methods, with 8 articles highlighted via in-depth commentaries.

A total of 35 papers were published in the Biology and Medicine section of $I U C r J$ in 2019, representing approximately $30 \%$ of the total papers published. In addition, papers in several other sections described applications in structural biology or medicine. It is evident that the biological sciences are a major source of high-impact crystallographic publications, and it is important that this momentum should be maintained.

The Chemistry and Crystal Engineering section of the journal continued to make good progress in 2019. There were 35 submissions of which 27 articles were voted for review. A total of 24 articles were accepted for publication, with 4 rejected and 2 still in review at the end of the year. These numbers are satisfying, but one would expect around 50 submissions every year (one per week). This section continues to pull its weight in contributing to the impact factor of 4.8. At the present time, one would hope to see more submissions in frontier areas where fundamental concepts are advanced in keeping with the overall goals of IUCrJ. The present Coeditors of the Chemistry and Crystal Engineering section of the journal are M. Eddaoudi, P. Lightfoot, L. R. MacGillivray and C.-Y. Su. We are on the lookout for a Co-editor in the important charge-density area.

Submissions to the cryo-EM section of $I U C r J$ have been growing, with 17 articles published in 2019. Cryo-EM publications feature strongly in the list of most read articles in $I U C r J$, and have also been well cited.

The other sections of the journal, covering Materials and Computation, Neutron and Synchrotron Science and Technology, and Physics and Free Electron Laser Science and Technology have published 21, 14 and 8 papers, respectively, in 2019.

The objective of $I U C r J$ remains to attract high-quality science papers of broad scientific significance from across all the scientific communities that use results obtained from diffraction methods. We hope that you will consider publishing in $I U C r J$ and, by doing so, help to further establish the journal as one of the mainstream comprehensive science journals.

D. Argyriou, E. N. Baker, C. R. A. Catlow, G. R. Desiraju, J. C. H. Spence and S. Subramaniam, Editors

\subsubsection{Acta Crystallographica Section A}

The number of submissions to Acta Cryst. Section A during 2019 was high (possibly as a consequence of the recent high impact factor) and the number of published articles was also 
higher than in recent years. Fifteen research papers were chosen on the basis of novelty and potential impact to be published as Advances, one of which was discussed in an accompanying scientific commentary and several of which featured on the covers. We note that in general Advances papers are amongst our most highly downloaded and cited articles. Almost a third of our papers were published as open access, which also tends to boost the number of downloads.

We are grateful to Gloria Borgstahl, Pat Thiel and Alan Goldman for selecting interesting articles from the Aperiodic 2018 conference on which to base a special issue. Pat and Alan acted as Guest Editors for a collection of eight excellent openaccess articles. Once all eight had been published in regular issues of the journal, they were collected together on their own web page along with an Editorial to form a 'virtual' issue, which was then publicized. These articles have been popular with our readers and are already collecting significant numbers of citations.

The average publication time has been increasing over the last few years. Possible reasons for this might include the high number of submissions, the increase in the average length of the articles and the complexity of some (particularly the more mathematical and theoretical articles, which can take a long time to review and to typeset). Our Co-editors often report that it is difficult to find appropriate referees who can deliver their reviews promptly, as there are only a limited number of experts who are able and willing to provide high-quality reviews for these kinds of articles.

Our 2018 impact factor (1.9) was somewhat disappointing. The decrease was partly a consequence of two highly cited articles, on SHELXT and OLEX, passing out of the calculation 'window'. We do not think it is appropriate to judge the journal by impact factor alone, as many of our articles describe new methods and techniques that sometimes take a while to be adopted by the crystallographic community, so might be slow to gather citations. The value of Acta $A$ articles is probably better reflected by the cited half life, which is consistently greater than 10 years. However, we are aware that while many of our articles are highly read and cited, a significant number attract relatively little interest and might not be cited at all for some time, thus pulling our impact factor down. We have been working with our Co-editors and the Editorial Office to try to improve the 'discoverability' of these papers by ensuring that the titles, keywords and abstracts all contain appropriate phrases that potential readers are likely to search for. We also see a role for scientific commentaries in explaining to a wider audience the relevance of a new piece of research, and often try to commission a commentary on interesting but highly mathematical articles to encourage more readers to such articles.

We were delighted to welcome three new Co-editors during 2019: Paulina Dominiak, Uwe Grimm and Ivan Vartaniants. Our thanks go to all our Co-editors for handling the high number of submissions during the year while ensuring that the standard of articles stayed high. We plan to appoint more Coeditors in 2020 to cover approaching retirements and new subject areas, and to help our existing board members with the workload. We are also looking forward to working with the new Commissioning Editors on a range of projects to develop the journal further.

A. Altomare and S. J. L. Billinge, Editors

\subsubsection{Acta Crystallographica Section B}

Acta Crystallographica Section $B$ continues to publish six issues per year. In 2019 the journal achieved the highest numbers of submissions (201), published papers (136) and pages (1227) in recent years, in part because of the publication of a very substantial Special Issue on Electron Crystallography helmed by Guest Editors Joke Hadermann and Lukas Palatinus. We anticipate that the impressive articles in this special issue will be well cited.

The unusually high rejection rate in 2018 (43\%) returned to a more normal value of $32 \%$ for the journal in 2019: this occurred naturally rather than as a result of any specific action by the Section Editors. The average length of papers has reduced from 10.7 to 9.7 pages, suggesting there is no general trend towards longer papers. The proportion of papers from China, France and Russia increased while decreases were noted for Australia, Canada and Germany: the top three countries were Russia (17\%), China (14\%) and Poland (7\%). The publication time lengthened slightly, from 5.0 to 5.2 months, as expected when a substantial special issue is published.

Last year the journal's impact factor reached a record 6.7, mostly owing to a very small number of highly cited Feature Articles which will no longer count towards this year's impact factor. As a result, we anticipate a considerable reduction. The journal aims to continue publishing Feature Articles and special issues, and we look forward to working with new Commissioning Editor Professor Elena Boldyreva.

New Co-editor appointments are under consideration and the outcome will be announced later this year: we are continuing to address issues of geographical spread and gender imbalance. We would like to express our thanks to the Guest Editors of the Special Issue on Electron Crystallography and to the Chester staff, especially the Acta B Managing Editor Amanda Berry, for all their support.

\section{A. J. Blake, M. de Boissieu and A. Nangia, Editors}

\subsubsection{Acta Crystallographica Section C}

Our efforts to make the journal more chemically relevant have continued this year. We have encouraged authors and Coeditors to produce papers that have a higher chemistry content and tell a story in which the structural data are central. The success of this strategy is illustrated by the increase in the average page length of the full articles published, which is 8.2 pages for 2019; up from an average of 7.7 pages in 2018. This continues the trend in increasing page length over the last five years. In terms of overall statistics, the total number of manuscripts received, 406, was slightly down on the 441 received in 2018, when a special issue was published. This resulted in a total of 197 published articles, with an increase in 
rejection rate to $49 \%$, up slightly on previous years. Many of these rejected papers are being resubmitted to Acta E. As in 2018, three Feature Articles have been published in 2019, which have attracted some interest and two of these feature in the list of the highest number of downloads for Acta C in 2019. In 2019, Acta $C$ has also started publishing scientific commentaries. Six were published, up from zero in previous years. Anecdotally, these have proved popular with the authors of the articles to which they refer.

The impact factor for Acta C for 2018 was 0.93 , which is a return to normality after the heady days of the impact factors for 2016 and 2017 where it reached over 8 because of two very highly cited articles featuring SHELX and PLATON which have now gone out of the citation window. Unfortunately, the Section Editors have not been able to commission articles that would have the same impact despite significant efforts to do so. On the positive side, there is a likely increase to around 1.0 predicted for the 2019 impact factor. The Editors look forward to working with the IUCr Commissioning Editors to increase the impact of the journal.

During 2019 there have been a number of retirements from the group of Co-editors and we wish to express our thanks to all the retirees for all the hard work they have put in over the years and for their continuing support for the journal. As a result of the retirements, Acta $C$ has taken the opportunity to recruit 11 young and enthusiastic new Co-editors from geographically diverse locations around the globe in order to increase the impact of the journal to new audiences. At the same time the Review Board is being refreshed, with a view to broadening the expertise in the review process to include diverse areas of chemistry that will provide more expert refereeing across the range of chemistry now being published in the journal.

The Section Editors would like to thank all the Co-editors and Review Board members, past and present, for their support of the journal. Finally, we would wish to express our thanks to the Chester Editorial Office staff who have maintained an outstanding professional standard throughout the recent turbulent times, and without whose hard work and dedication the journal would simply not exist.

Paul Raithby, Larry Falvello and Jonathan White, Editors

\subsubsection{Acta Crystallographica Section D}

There are again signs that Acta $D$ is recovering from the effects of the impact factor having dropped six years ago, when several highly cited methods papers disappeared over the limited horizon of the impact-factor calculation. The number of submissions and published papers has plateaued for the last four years at around 160. The impact factor of 3.2 is slightly better than last year and good relative to the historic range of 2 to 3 . A higher proportion of papers were rejected $(29 \%)$ compared with 2018 (19\%), resulting in a drop in the number actually published. We were pleased to publish two Feature Articles (in June on the EM facility at the ESRF and in October on new tools in Phenix for dealing with data collected using X-ray, neutrons or electrons) during the year, both of which reflected the expanding remit of structural biology methodology. Sadly, there were also four obituaries of structural biologists who had made enormous contributions to the field (Tom Steitz, Aaron Klug, Michael Rossmann and Barbara Low).

Special issues continue to play a positive role for the journal. Last year there was only one complete special issue, that from the CCP4 Study Weekend on the topic of 'Multi and serial data collection and processing', which was published in February. It is of note that there were also 5 papers published from the CCP-EM Spring Symposium ( 2 in May, and 1 in each of September, October and December) reflecting the decision to include these papers when they are first accepted and typeset rather than waiting until all the papers in preparation are ready. These will be collected in a 'virtual special issue' once all the remaining papers are accepted.

No new Co-editors were appointed over the year, but three more are currently under consideration and have agreed to serve if approved. The addition of these new Co-editors will cover an expansion into different areas of structural biology, particularly electron microscopy. Additionally we hope to recruit a third Section Editor.

Publication times are down by around three weeks compared to 2018 and back at the 2017 level. It should be noted that these are driven largely by the time required for refereeing and manuscript revision, but very little by technical editing or typesetting, which are both highly efficient thanks to the excellent work by Louise Jones and Simon Glynn in the Chester office, under the supervision of Executive Managing Editor Peter Strickland and Editor-in-chief Andrew Allen.

\section{E. F. Garman and R. J. Read, Editors}

\subsubsection{Acta Crystallographica Section $E$}

In the last year the number of submissions and publications decreased slightly compared to 2018 but the journal continues to attract papers from across the world, with authors from 66 countries publishing in Section E in 2019. There were increases in the proportion of papers from Germany, Morocco and the Ukraine in Section $E$ while the proportion of papers from China and Russia decreased. The top five countries were the USA (14\%), India (12\%), Germany (9\%), Morocco (7\%) and Turkey (6\%). The number of downloads for Section $E$ articles was 5.7 million in 2019, by far the largest number for an $\mathrm{IUCr}$ journal.

Papers are generally getting longer: the average length increased further to 5.0 pages, and the average publication time slightly to 1.3 months. We are increasingly receiving manuscripts reporting two or more structures and describing Hirshfeld surface analysis, energy frameworks and the results of complementary techniques such as DFT calculations.

The Section Editors identify articles that do not contain sufficient scientific discussion at the pre-screening stage; these are either transferred to IUCrData or resubmitted after the authors have improved the content. The Section Editors have been actively trying to commission papers that will be widely 
read and highly cited. The first of these, on Hirshfeld surface analysis, was published in March 2019, followed in December 2019 by some reflections on symmetry and the pitfalls of automation. The series will be continued in 2020 with papers on checkCIF, and tips and tricks for obtaining the best results.

As always, we are extremely grateful to our Co-editors for the excellent work they do and cannot thank them enough. Many of our long-standing Co-editors have retired recently or are due to retire at the end of 2020. Potential new Editorial Board members have been identified and their nomination is in progress. In July 2019 Section Editor Elena Boldyreva moved to become IUCr Journals Commissioning Editor for Chemistry and Chemical Crystallography and Sean Parkin was welcomed as a new Section Editor. In addition, Helen Stoeckli-Evans stepped down as a Section Editor at the end of 2019 and Graciela Diaz de Delgado joined the three remaining Section Editors.

We are grateful for the excellent support that we receive from the staff in Chester, particularly Gillian Holmes, Sean Conway and Mike Hoyland, for their constant help and support, and Peter Strickland for his sound advice and expert guidance.

G. Diaz de Delgado, C. Massera, S. Parkin and L. Van Meervelt, Editors

\subsubsection{Acta Crystallographica Section F}

Acta Crystallographica $F$ is a home for short and rapid structural biology communications, welcoming manuscripts covering a range of techniques, including crystallography, cryo-electron microscopy, NMR spectroscopy, SAXS and computational approaches. Preliminary results, such as crystallization notes, are now accepted if the system studied is novel, or if the method has new aspects that may be useful for researchers working on other systems. The impact factors and cited half-life have increased since 2014 but the number of published papers remains low - we need to attract more authors. The average publication time has risen to over three months and this may be related to the average length of manuscripts, which has increased in line with an increase in manuscript quality.

In 2019, the following new Co-editors were recruited: Linda Shimon (Weizmann Institute, Rehovot, expert in macromolecular crystallography, molecular recognition and organometallic compounds), Yang Chen (MAX IV Lab, Lund, expert in protein crystallography, integrative structural biology, method development and synchrotron methods), Jon Agirre (University of York, expert on carbohydrate chemistry, glycobiology, method development, computational crystallography and protein crystallization) and Mike Hough (University of Essex, expert on biological crystallography, serial crystallography, XFELs, crystallographic methods, metalloproteins and radiation damage). Plans have also been made to refresh the Review Board with new additional members.
The strengths of the journal include the fast but high-quality scientific and technical editing, its standing in the crystallographic community and its goodwill, by virtue of it being a scientific society journal. However, the impact of the journal and its familiarity to non-crystallographic structural biology communities need to be increased further.

It will be important to continue to grow the journal in terms of quantity and quality of papers, but also to maintain the philosophy of short and rapid communications, to distinguish it from Acta Cryst. D and IUCrJ. To achieve this, various initiatives are planned. Topical Reviews and special issues on interesting topics are being pursued; for example, a number of papers on cryo-EM were published in January 2019, and more special issues will hopefully follow. We continue to procure inaugural articles from new Co-editors, but further effort will need to be made here. Potentially, developing novel article categories and novel publishing procedures will also increase the authorship and the scientific audience. With this in mind, a new article type, Methods Communications, was introduced in 2019 to provide researchers with quick tips as well as more detailed methods. Hopefully these and future efforts will result in more impact for Acta Cryst. F.

\section{J. Newman and M. J. van Raaij, Editors}

\subsubsection{Journal of Applied Crystallography}

In 2019, Karena Chapman joined Janos Hajdu and Garry McIntyre as a Main Editor of Journal of Applied Crystallography. Karena is Professor in Materials Chemistry at Stony Brook University and has been a member of $J A C$ 's Editorial Board since 2014, when she joined as a Co-editor.

One more appointment that we expect will have a favourable impact on the journal is that of another of our Co-editors, Thomas Proffen, as the new Commissioning Editor for Materials, Methods and Instrumentation. The role of the Commissioning Editors is 'to work across all relevant IUCr journals in commissioning high-quality individual papers and special issues, and hopefully attract authors, reviewers and Editors who have not worked with IUCr journals previously'. We all look forward to continuing to work with Thomas in what we hope will be an exciting new era for $J A C$.

We will also be further expanding the Editorial Board with a number of Co-editor appointments in 2020.

The numbers of papers submitted to and published in the journal have been falling off slightly in the past few years, probably as a result of the fall in impact factor. The rejection rate remains above $30 \%$, and the publication time and average paper length are stable.

A special issue on ptychographic software and technical developments is underway, with publication expected in the summer of 2020. The Guest Editors are Stefano Marchesini and David Shapiro from Lawrence Berkeley National Laboratory, and Filipe Maia from Uppsala University. A crossjournal special issue on machine learning is also in the planning stages.

K. Chapman, J. Hajdu and G. J. McIntyre, Editors 


\subsubsection{Journal of Synchrotron Radiation}

The number of papers published continued to rise in 2019 249 papers were published compared with 222 in 2018 and 156 in 2017. The number of pages published rose to 2096 for 2019 , compared with 1894 and 1300 for the previous two years. The number of accepted papers also rose - 249 in 2019 compared with 211 in 2018 and 164 in 2017. The rejection rate returned to its 2017 value of $25 \%$, from $20 \%$ in 2018 . Publication times stayed about the same at 5.7 months (5.6 in 2018 and 2017).

One special issue was published in 2019 - selected papers from the 10th International Workshop on X-ray Radiation Damage to Biological Crystalline Samples, a recurring series that has been published in JSR every two years since 2002. Forming part of the July 2019 issue, the Guest Editors were again Elspeth Garman and Martin Weik, and the issue featured ten special issue papers totalling 103 pages.

A number of virtual issue papers were published for the first time in $J S R$ in 2019 - virtual issues being essentially special issues where instead of the papers being published together in one issue they are published as soon as they are ready over a number of issues. Main Editor Ilme Schlichting organized a virtual issue of 30 papers on X-ray free-electron lasers that were published across the March to September 2019 issues, and 17 papers from the PhotonDiag 2018 Workshop were published across the May 2019 to January 2020 issues.

$J S R$ is continually looking to publish such themed issues of selected papers from workshops or meetings, because as well as providing an important service to the synchrotron-radiation community they are a good way for the journal to expand into new areas and to attract new authors and readers.

Regarding the JSR Editorial Board, Main Editor Mikael Eriksson retired in early 2019. Owing to the increase in submissions over recent years it was agreed that more Coeditors were needed to share the workload. Five new Coeditors were appointed in 2019: Anna Bergamaschi (PSI, Switzerland), U-Ser Jeng (NSRRC, Taiwan), Kristina Kvashnina (ESRF, France), Andrew Stevenson (Australian Synchrotron) and Meitian Wang (PSI, Switzerland). The Editorial Board now comprises three Main Editors and 16 Coeditors.

The Facility Information pages continued in JSR in 2019, providing an opportunity for facilities to communicate important news and updates to the international community of synchrotron-radiation users. In 2019, facility pages were provided by the Advanced Photon Source, Paul Scherrer Institute, MAX IV and LAAAMP (Lightsources for Africa, the Americas, Asia and Middle East Project).

We thank the readers of $J S R$ for their continued interest and support, the authors for publishing in our journal, and the Co-editors for their great service to the journal and to the community.

\section{Y. Amemiya, I. Lindau and I. Schlichting, Editors}

\subsubsection{IUCrData}

During 2019, the number of papers submitted to IUCrData dropped somewhat compared with those in 2018 and more significantly in comparison to the two previous years. This may reflect the fact that crystallographers may decide to simply deposit one-off structures or those that cannot be included in more substantial papers with the Cambridge Structural Database with the deposition getting a doi and avoid the cost of a peer-reviewed publication. The fact that Acta E numbers have not shown a similar downward trend also suggests that authors are willing to put more effort into reporting their structures more comprehensively. Papers received by the journal came from authors in 30 countries in 2019. The USA heads the list with $18.0 \%$, closely followed by India with $17.5 \%$ and Germany next at $10.8 \%$.

We are enormously grateful to Professor H. Stoeckli-Evans, one of the founding Main Editors of IUCrData and latterly a Co-editor, who retired recently. Thanks also to the excellent team of current Co-editors who do a terrific job and without whom the journal would not exist. As always the help and advice of Gillian Holmes and the great team in Chester, who are always there to support us, is much appreciated.

W. T. A. Harrison, J. Simpson, E. R. T. Tiekink, L. Van Meervelt and $\mathbf{M}$. Weil, Editors

\subsection{Commission on International Tables}

International Tables for Crystallography is a book series published by the IUCr in conjunction with Wiley. Nine volumes designated A (and A1) through $\mathrm{H}$ are currently in print. Parts of a tenth (I, on X-ray absorption spectroscopy and related techniques) have been received and many of the articles have been accepted. The Brief Teaching Edition of Vol. A (Space-group symmetry) is also part of the series; a revised edition is expected to appear in 2020. The Symmetry Database is a related online resource.

Historically the series has been composed of print volumes but online versions started appearing in 2006. While printed copies of all volumes are still available for individual purchase they may not remain so indefinitely because economic considerations so greatly favour annual online subscriptions to the entire series. The symmetry tables (e.g., Vols. A and E) are, however, expected to remain available in both formats. So far the Brief Teaching Edition has appeared in print only.

A series that is largely electronic allows greater flexibility; parts of new and revised volumes can appear online in advance of completion of the entire volume and problems identified after publication can be fixed quickly. This scheme was first used for Vol. H (Powder diffraction), which appeared in print in 2019. Authors who complete their chapters promptly appreciate not having to wait for all the articles to be finalized. This approach also makes it easier to meet Wiley's annual target of $10 \%$ new or revised content.

Descriptions of activities during 2019 for the individual volumes follow.

Vol. A (Space-group symmetry; most recent online edition is dated 2016; Editor Mois Aroyo). During 2019, the text and the tables of reflection conditions of the chapter on spacegroup determination (Chapter 1.6) were extended to include the so-called 'diffraction symbols' (known also as 'extinction 
symbols') that had been present in the previous edition. The typesetting of the new text and tables was completed and the preliminary proofs were checked by the author (Uri Shmueli), but before the new chapter is put in the online edition it will be reviewed by several more experts.

Symmetry Database server of the Online Edition of International Tables (updated continuously; Editor Mois Aroyo). The work on the enhancement of the Symmetry Database of the online edition of International Tables for Crystallography continued through 2019 within the framework of the project between the IUCr and the software company eFaber (Bilbao) and in collaboration with the Bilbao Crystallographic Server team. The main activities have centred on:

(i) final development, testing and implementation of additional computer tools for the analysis of group-subgroup relations of space groups including a user-friendly, step-bystep procedure for the transformation-matrix determination of a given group-subgroup pair; and

(ii) further development and implementation of the website of the Teaching Edition of the Symmetry Database.

Suggestions have been received recently from Chester for improvements in the layout and style of data presentation of the interfaces for the Teaching Edition and the step-by-stepprocedure. Work on the implementation of these recommendations is well advanced; in a relatively short time it should be possible to show the modified and corrected version of the websites.

BTE (Brief Teaching Edition of Vol. A; current edition is dated 2010; Editor Mois Aroyo). Almost all of the material for the considerably revised version is awaiting typesetting in Chester; completion in 2020 is anticipated. The new version is designed more specifically for people new to the field of crystallographic symmetry. The revision will also serve as an introduction to Vols. A1 and E of International Tables, to magnetic space groups, and to the Symmetry Database, i.e., to a broad set of topics in crystallographic symmetry, some of which are still being developed.

Vol. A1 (Symmetry relations between space groups; most recent online edition is dated 2011; Editor Ulrich Müller). A search for a Co-editor is underway. The expansion of Vol. A1 (or possibly Vol. E) to cover the subperiodic groups remains under consideration.

Vol. B (Reciprocal space; most recent online edition is dated 2010; Editors Gervais Chapuis \& Michal Dušek). Much of the material in Vol. B is timeless so that there is no pressing need for a new print edition. Several new and revised articles are, however, being prepared for the online edition. One of those is a revision of Ted Janssen's article on modulated structures (currently Chapter 9.8 of Vol. C), which he had completed before his passing in 2017. That article will be combined with Chapter 4.6 of Vol. B (Reciprocal-space images of aperiodic crystals). There are also articles in progress on 3D pair distribution functions (3D-PDF) and on charge flipping.

Vol. C (Mathematical, physical and chemical tables; online edition is dated 2006; Editor Richard Welberry). Many of the articles for this essentially new volume have been completed.
It is anticipated that some of them will appear in the online edition before the end of 2020 .

Vol. D (Physical properties of crystals; most recent online edition is dated 2013; Editor André Authier, who has since retired). Attempts to find a new Editor for Vol. D have been unsuccessful, but it seems that there is no immediate need for a revision.

Vol. E (Subperiodic groups; most recent online edition is dated 2010; Editor Danny Litvin). Danny Litvin will retire as Editor during 2020. Several possible successors have been identified.

As interest in two-dimensionally periodic materials like graphene increases, interest in Vol. E is expected to grow. Suggestions for extensions have been received; they include adding tables of penetration rod groups, allowing searches for all space groups for which a specific layer group is a sectional layer group, and revising the text to make it more accessible to readers who are less expert in mathematics.

Vol. F (Crystallography of biological macromolecules; most recent online edition is dated 2012; Editors Liang Tong, Eddy Arnold, and the late Michael Rossmann). A plan for the content of the third edition of Vol. F was finalized in 2018, but a number of considerations led the Executive Committee to request that work on a new edition be postponed. The current plan is to start contacting authors in late 2020 , with the finalized manuscripts expected in 2021.

Sadly, Michael Rossmann passed away in May 2019, which was a terrible loss for structural biology and science in general. The remaining Editors have decided to dedicate this new edition to his memory.

Vol. $G$ (Definition and exchange of crystallographic data; online edition is dated 2006; Editors Brian McMahon and James Hester). Progress on the second edition of Vol. G proceeded during 2019 at a steady, if slow, pace. Drafts of chapters describing the new standards for dictionaries are near completion, and an automated process for updating dictionary chapters from the first edition to meet the new standards has been developed. The Editors had a productive face-to-face meeting during the year; 2020 should see the chapters on the fundamental standards completed and refereed, with the chapters relating to the dictionaries in advanced draft form.

Vol. H (Powder diffraction; new volume in 2019; Editors Henk Schenk, Chris Gilmore and Jim Kaduk). Vol. H, the first new volume since 2012, appeared in 2019. It has already sold well (150 copies) and has already generated a list of suggested additions and improvements. Jim Kaduk and Chris Gilmore will continue as Editors; they have identified a replacement for Henk Schenk, who is expected to retire.

Vol. I (X-ray Absorption Spectroscopy and Related Techniques; new volume; Editors Chris Chantler, Federico Boscherini and Bruce Bunker). All Editors of Vol. I have been working diligently, and good progress has been made. The plan is to post major sections online as they are finalized, typeset and proofed; it is hoped that 2-3 main sections might get to that point during 2020. The quality of the articles is in general excellent and will make a major contribution to the literature, reference works and field. 
Further information about the volumes can be found at the home page of the Commission, http://www.iucr.org/resources/ commissions/international-tables. The 'Guided Tour' available at http:/it.iucr.org/services/guidedtour/ is highly recommended because it shows what is available electronically. Access to the Tables of Contents of all the volumes is free, as are sample pages (including author lists and prefaces); see the home pages for the individual volumes (e.g., http://it.iucr.org/ $\mathrm{A} /$ ).

Central to the success of this series are the contributions of the staff in Chester, and especially of Nicola Ashcroft. As always they have applied their considerable expertise in layout, typesetting and insertion of hyperlinks. They have helped authors and Editors by answering questions about standard practices and by tactfully suggesting ideas for clarifying text. Having an Editor with writing as well as technical skills is a very great asset. The Chester staff has also been very helpful in finding ways to take advantage of advances in electronic publishing while at the same time working to preserve print publication.

Carolyn P. Brock, Chair

\subsection{Commission on Aperiodic Crystals}

The Commission on Aperiodic Crystals (CAC) paid a heavy toll in 2019; An-Pang Tsai, Professor at Tohoku University, Sendai, Japan, and a leader in the field of quasicrystal and complex intermetallic research, passed away on 25 May 2019. He will surely be missed by the community.

Our flagship scientific event in 2019 was the 14th International Conference on Quasicrystals (ICQ14), which was held at Kranjska Gora, Slovenia, 26-31 May 2019. The conference, which was chaired by Janez Dolinšek, is the fourteenth in the series of triennial conferences organized under the auspices of the CAC, with the Jožef Stefan Institute, the Ljubljana Faculty of Mathematics and Physics and the University of Ljubljana Institute of Mathematics, Physics and Mechanics, Ljubljana, as the local organizers. The conference was attended by 84 delegates from more than 20 countries. In the five conference days, a broad range of topics were covered, including formation, growth and phase stability; structure and modelling; mathematics of aperiodic order; physical properties; surfaces and thin films; quasiperiodic soft matter; new frontiers; applications; and related topics. At ICQ14, the 2019 JeanMarie Dubois Award for Excellence in Quasicrystals was presented to Professor Alan Goldman of Iowa State University. The award was given for 'elucidating the relationship between quasiperiodicity and magnetism, particularly through the ground-breaking discovery of a series of binary $\mathrm{Cd}$-rare earth icosahedral quasicrystals, measurement of their magnetic properties, and comparison with the parent $1 / 1$ periodic approximant'. The Commission wishes to express its gratitude to Janez Dolinšek as well as the entire team who made this event a success. For more details, see the conference website at http://icq14.ijs.si/.

In 2019, the CAC also organized the 4th International School on Aperiodic Crystals in Portbail, Normandy, France, with the support of the CNRS (formation permanente), the Normandy council, the European CMAC network and different other more modest subscribers. The IUCr provided six grants for promoting women in science. The school, which followed on from the successful schools in Carqueiranne, France, in 2010, Bayreuth, Germany, in 2013, and Antwerp, Belgium, in 2016, attracted 32 participants from 13 different nations. Teaching at the school was provided by nine lecturers. This school is our central educational activity, with the objective of providing an overview of aperiodic order, of the basics of the mathematical description of both modulated structures and quasicrystals, and of physical properties and chemical understanding of aperiodic crystals, as well as a working knowledge of structural analysis of aperiodic crystals.

Further events supported by the Commission in 2019 include the JANA2006 ad hoc workshops in Prague, Czech Republic. Details of the workshops (Nos. 36, 37 and 38) can be found at http://jana.fzu.cz. In addition, an Interdisciplinary Symposium for Quasicrystals and Strongly Correlated Electron Systems was held at Tohoku University (Tokyo, Japan), 23-27 June 2019.

Two upcoming and important meetings for the Commission should be mentioned. The first is the 10th International Conference on Aperiodic Crystals (Aperiodic 2021) to be held in Sapporo, Japan. The second is the 25th IUCr Congress in Prague, with two microsymposia and one keynote lecture directly related to aperiodic crystals. The Commission is also planning a one-day satellite workshop, Introduction to Aperiodic Crystals.

O. Pérez, Chair

\subsection{Commission on Biological Macromolecules}

The aim of the Commission on Biological Macromolecules (CBM) is to support macromolecular crystallography worldwide by promoting scientific exchange, training, and policies that encourage the generation and dissemination of knowledge and technologies.

The availability of diffraction data. The CBM coordinated its efforts with the IUCr Committee on Data (CommDat) and Editors of IUCr journals to further evaluate the practical aspects of the deposition of diffraction images, which constitute the primary data in a macromolecular X-ray diffraction experiment. The Executive Committee approved the White Paper entitled Proposed mechanisms for making diffraction experiments available. Subsequently, several IUCr journals published the editorial Findable Accessible Interoperable Reusable (FAIR) diffraction data are coming to protein crystallography, which is co-authored by the Chair of CommDat, the Chair of the CBM, and the Editors of the journals. The CBM Chair sent this paper to many labs when requesting data related to important biological and methodological projects, including COVID-19 data. As of July 2020, data for over 9000 diffraction experiments have been submitted to the two most 
popular servers of diffraction data. However, many people still refuse to submit diffraction data even when requested. A recent example is COVID-19 related projects. Out of 133 structures deposited in the Protein Data Bank (PDB), only ten complete data sets have been deposited in a public repository.

Standards for data to be provided to reviewers of macromolecular structures. The CBM has continued to work with the American Crystallographic Association, the Asian Crystallographic Association, the European Crystallographic Association and the Worldwide Protein Data Bank (wwPDB) to continue the development of standards for information that reviewers of macromolecular structures and the public (after PDB deposition) should receive. There is an agreement that reviewers should receive (1) the PDB validation report and (2) pictures of omit maps for any ligands and unusual structural elements. Additionally, the draft standards suggest making the data (structure factors, coordinates) available to reviewers. The CBM continued the discussion about the deposition process and modelling standards. The ultimate goal is to set the standard of deposition of models that describe the disorder within structures.

IUCr Congress. The discussion about the programme of IUCr Congress in Prague involved three CBM representatives (Alice Vrielink, Julie Bouckaert and Marcin Nowotny) and some members of the CBM. Unfortunately, the Congress has been postponed until August 2021.

Meetings, workshops and other outreach activities. The CBM has recommended support from the IUCr for a number of meetings and workshops that can provide teaching or play a significant role in the dissemination of data in macromolecular crystallography. However, owing to the COVID-19 health crisis, most of these meetings are being cancelled or moved to 2021.

Identification of labs depositing the structures without a 'primary citation'. During recent years, the number of deposits that cite 'To be published' instead of a journal as the primary citation has grown significantly. As of 12 June 2020, there were over 26000 PDB deposits that have 'To be published' status, and over 9000 deposits have had this status since 2010, i.e. for ten years. Core metadata are very important for biomedical scientists as well as structural biologists. However, when we are working on a similar structure we often need additional information that is impossible to get from the PDB deposit alone. In particular, when a PDB deposit has a journal publication as a primary citation, it is very easy to find an e-mail address of the senior author (or depositing author) and contact that person if the need arises. Unfortunately this is often not possible in the case when the primary citation has 'To be published' as its status in the PDB. The Chair of the IUCr Commission on Biological Macromolecules, the Chair of CommDat and 26 other senior crystallographers proposed that every PDB deposit should have in the metadata for the deposition the work institution e-mail address of the senior author.

Wladek Minor, Chair
4.5. Commission on Crystal Growth and Characterization of Materials

The work of the Commission in 2019 was mainly devoted to the organization of the IUCr Congress in 2020. Our commission suggested and supported the organization of several microsymposia, including (i) The Mineral/Life Interface: From Prebiotic Chemistry to Biomineralization and Advanced Biomimetic Materials, co-chaired by Professor García-Ruiz (Spain) and G. Falini (Italy); (ii) Facets and Twinning in Bulk Crystal Growth, chaired by Professor Thierry Duffar (France); (iii) Applications of Electron Crystallography to Functional Materials; (iv) Novel Techniques and Insights into in vitro and in situ Crystallization for X-ray and Electron Diffraction, cochaired by Professor Louisa Meshi (Israel) and Professor Janet Newman (Australia); (v) Layered 2D Type Crystals with Varying Polytypes, co-chaired by Professor Matteo Bosi (Italy); and (vi) Frustrated Magnetic Order and Emerging Science, chaired by Professor Geetha Balakrishnan (UK). A keynote speaker was also suggested: Juan Manuel Garcia Ruiz, who was finally selected.

Related to the organization of the IUCr Congress, the Commission was asked to prepare a document about the future trends of crystal growth. Most of the members/consultants contributed to this paper.

The members and consultants of the Commission had the chance to meet on 29 July 2019, at the 19th International Conference on Crystal Growth in Keystone, Colorado, USA. [This is the most important event organized by the International Organization for Crystal Growth (IOCG), and is described in more detail in Section 13.6.] The commission meeting was attended by Thierry Duffar, Elias Vlieg, Koichi Kakimoto, Jiyang Wang, Katsuo Tsukamoto and Andrea Zappettini. It was also attended by Hanna Dabkowska and Antonio Vecchione.

Because the IUCr Congress was approaching, and so the renewal of the composition of the Commission, the availability of present members or consultants as candidates for the next Commission Chair was verified. Members and consultants that were not at the meeting and that are available to be Chair were also invited to be candidates.

Hanna Dabkowska reported that the paper we wrote (Current trends and future in crystal growth: a report from the Commission on Crystal Growth and Characterization of Materials of the International Union of Crystallography) was very much appreciated by the conference organizers. We decided to explore whether a refined version of it could be of interest for publication in one of the IUCr's journals.

Finally, we considered the situation of the Crystal Growth Schools that will be organized in the next few years. While in 2022 there will be the ISSCG18 in Naples and in 2021 the ESCG3 in Paris, for 2020 there are at the moment no requests of support for any international conference. It was stressed that the Commission is always available to support requests for funding by the IUCr for international schools on crystal growth, as well as to support local organizers by suggesting good lecturers and offering practical information. 
In 2019 the IUCr supported the following schools/meetings that were important for the crystal-growth community:

7th International School on Biological Crystallization (ISBC2019), Granada, 26-31 May;

International Summer School on Crystal Growth ISSCG17, Colorado, USA, 21-27 July;

2019 Gordon Research Seminar on Crystal Growth and Assembly;

19th International Conference on Crystal Growth and Epitaxy (ICCGE-19), Keystone, Colorado, USA, 28 July - 2 August; and

6th Directionally Solidified Eutectics Conference (DSEC VI), Department of Physics of the University of Salerno in Salerno, South Italy, 10-13 September.

Finally, I would like to express my great honour and pleasure to be chairing this commission. I hope I am making my own contribution to all the work done up to now by the Commission to bring more understanding of the role of crystals and their influence on many aspects of life and technology.

\section{A. Zappettini, Chair}

\subsection{Commission on Crystallographic Computing}

In 2019 there were no changes to the members or consultants of the Commission. There were no meetings of the Commission, and no schools or conferences were organized by the Commission.

In 2019 the Commission wrote letters of support for the school Expo\&more in Bari, Italy (2019) and for the International School of Crystallography in Erice, Italy (2020). The Commission also supports its own Crystallographic Computing School, which was planned as a satellite of the IUCr Congress in Prague in 2020, now postponed to 2021.

In 2019 there were no activities of the Commission related to IUCr publications and guidelines.

In addition to the fields with active computational research, the Commission recognizes four new fields with a need for new algorithms and tools: machine learning and artificial intelligence; algorithms for electron diffraction; dynamics in crystals; and serial crystallography.

The main event of the Commission for working on these new topics is the Crystallographic Computing School, which is being organized by the Commission in Nove Hrady as a satellite meeting to the main IUCr Congress in Prague.

Harry Powell maintains the Commission web page, which is up to date. The Commission thanks him for his efforts.

Interaction with other commissions is through the joint organization of microsymposia at the IUCr Congress.

Community building takes place mainly during the Computing Schools. Attendants are young crystallographers as well as senior programmers. The schools are a perfect opportunity for interaction and for shared programming activities. The Commission will additionally organize the Crystallographic Software Fayre during the IUCr Congress in Prague, at which developers can present the newest develop- ments and demonstrate them to the users, and users are able to meet software authors.

Martin Lutz, Chair

\subsection{Commission on Crystallographic Nomenclature}

The members of this commission (the $\mathrm{CCN}$ ) are the Editors of the Union's journals, the Editors of the volumes of International Tables, the Chair of the IUCr/OUP Book Series Committee, the Chair of the Teaching Commission, the Chair of the Committee for the Maintenance of the Crystallographic Information File Standard, and both the IUCr President and General Secretary. The total number of members and appointed consultants is $c a 50$. While ways to reduce the size of the $\mathrm{CCN}$ have been considered, the importance of all members is recognized. In the case of a matter needing the vote of the whole Commission, a Working Group composed of members representing all important viewpoints would be asked to prepare a report to be circulated to the $\mathrm{CCN}$ in advance of the vote.

Nomenclature problems. The Commission's web page invites crystallographers to bring nomenclature problems to the attention of any Commission member. The one matter that came up during 2019 concerned the definition of screw axes, particularly screw axes $\left(\right.$ e.g. $\left.5_{1}, 11_{3}\right)$ that are incompatible with the space groups listed in Volume A of International Tables for Crystallography. This matter arose in connection with an article for the revised edition of the Brief Teaching Edition (BTE) of Volume A. So far only informal discussions between Ulrich Müller (Editor, Vol. A1), Mois Aroyo (Editor, Vol. A and the BTE) and Carol Brock (CCN Chair) have taken place.

Online Dictionary of Crystallography (ODC), Editor Gervais Chapuis. The CCN is responsible for maintaining the ODC, which was established in 2006 as a wiki and continues to be run as such, i.e. as a website of definitions that qualified members of the crystallographic community can add to or modify. Snapshots of the ODC were published in paperback form in 2014 and 2017 (i.e. on the occasion of the two most recent IUCr Congresses).

The ODC has never generated much activity even though the IUCr commissions were charged by the Executive Committee during the 2017 Congress in Hyderabad to provide definitions for their areas of expertise. The ODC still has only 316 definitions, with only a few having been added in the last year. At least some of the new definitions were sent to the Editor, who himself entered them into the ODC. The number of authors who created new entries or revised existing definitions remained very small.

Some new definitions related to powder diffraction were added in connection with the publication of the new Vol. $\mathrm{H}$ of International Tables for Crystallography. New definitions are also being generated in connection with development of the new Vol. I on X-ray absorption spectroscopy and related techniques.

In an attempt to increase the number of entries in the ODC, Gervais Chapuis and Carol Brock wrote an article about it that appeared in the first 2019 issue of the IUCr Newsletter 
(see https://www.iucr.org/news/newsletter/volume-27/number$1 /$ the-iucr-online-dictionary-of-crystallography). That article generated a few requests for permission to contribute, but no new definitions.

It is noteworthy that IUPAC is also having problems with its dictionaries (the Colour Books, including the Gold Book). The Chair of the CCN is a member of the IUPAC Interdivisional Committee on Terminology, Nomenclature, and Symbols (the ICTNS), see Section 13.1. That committee has been circulating documents and meeting electronically to set up procedures for adding new definitions to the Gold Book. Considerable time is being contributed to this effort by some of the other ICTNS members but progress has been slow.

Other matters. Four articles related to $\mathrm{CCN}$ activities appeared in the 2019 issues of the IUCr Newsletter. The article about the Online Dictionary of Crystallography is described above. The intent was to increase interest and activity.

Consultant Massimo Nespolo contributed engaging articles to the 2nd, 3rd and 4th issues of the Newsletter. The Lattice Sickness Pandemic discusses the difference between a crystal lattice (a mathematical construct) and a crystal structure (https://www.iucr.org/news/newsletter/volume-27/number-2/ the-lattice-sickness-pandemic). The Super-Sub Schizophrenia points out that a superstructure is associated with a sublattice rather than with a superlattice (https://www. iucr.org/news/newsletter/volume-27/number-3/the-super-subschizophrenia). Crystallographic Flatland argues that the widely used adjective low-dimensional should be replaced by subperiodic (https://www.iucr.org/news/newsletter/volume-27/ number-4/crystallographic-flatland). Each of Nespolo's articles was highlighted in the issue's Editorial, written by $\mathrm{IUCr}$ Newsletter Editor and CCN Consultant Mike Glazer.

Carolyn P. Brock, Chair

\subsection{Commission on Crystallographic Teaching}

The Commission (the CCT) continues to be a large and vibrant group of nine regular members and 14 consultants. The members are Katherine Kantardjieff, Chair; Oluwatoyin Asojo, Vice Chair; Annalisa Guerri; Tsuyoshi Inoue; Pavel Kashkarov; Diego G. Lamas; Sol Lopez-Andres; Jarug Narasimha Moorthy and Manfred Weiss. The consultants are Mois Aroyo, Alexander (Sandy) Blake, Elena Boldyreva, James Britten, Saulius Grazulis, S. Krishnaswamy, Edward Michalski, Claudine Mayer, Claudia Rawn, Miriam Rossi, Nivaldo Speziali, Michele Zema and Shao-Liang Zheng.

Evaluation of applications for workshops and schools. Members and consultants are active in reviewing applications for workshops and summer schools. In each of the three application periods during 2019 the CCT reviewed 5, 4 and 8 applications or proposals, respectively. In the first two application periods of 2020, which were disrupted by the COVID19 pandemic, the CCT reviewed a total of 6 applications or proposals. All documents are shared mainly on Google Drive, while a few members and consultants continue to use e-mail. The evaluation process has been further streamlined with the use of standardized rubrics and an evaluation form, which facilitate clarity, objectivity, transparency and timely writing of evaluation letters. The CCT strives to provide letters of evaluation that are not only supportive but also informative to the applicants, the Sub-committee on the Union Calendar and the Executive Committee. We continue to advocate for the use of a centralized electronic submission process, which will improve workflow and reduce errors. We had planned to post instructions and a tip sheet for applicants on the website, so that applications are submitted to the appropriate person in the submission cycle, and so that the applications are prepared on current forms and are complete in required content. Unfortunately, the COVID-19 pandemic quarantines and lockdowns caused hardships for many colleagues around the world, and we have yet to complete this task.

Community outreach: social media and web resources. Since the 2017 Congress and General Assembly in Hyderabad, the CCT has continued its efforts to reach out to the crystallographic community, the scientific community and the community at large using social media. The commission Facebook page has been the most active, reaching a steady state of 1146 'likes' and 1173 followers (http://www. facebook.com/IuCrCommissionOnCrystallographicTeaching). Our Twitter feed activity has increased by 36\% (@IUCrTeach) with 245 followers. Social media use is highly generation dependent, and we continue to explore the potential use of Instagram and LinkedIn for enhanced outreach. Social media posting for intentional outreach takes concerted effort, and the amount of time the CCT members can devote to this is limited given their other professional responsibilities. The CCT is exploring transfer of account ownership to staff in the IUCr office before the commission membership changes in Prague. Social media accounts are currently owned and managed by Katherine Kantardjieff, and other commission members do not want the IUCr social media accounts attached to their personal accounts. Transfer of ownership to the IUCr staff will enable the CCT to assign members posting responsibilities to our social media, keeping our followers informed and engaged. In addition, this will enable more regular review and refreshing of our web resources.

On a personal note, I have decided not to continue as Chair for an additional year owing to professional commitments. The CCT Vice Chair, Toyin Asojo, will assume the role of interim Chair until the rescheduled Congress in 2021. I thank the IUCr for the opportunity to represent the CCT as a consultant, member and Chair for these many years. It has been a privilege and a pleasure to promote international cooperation in crystallography and to contribute to all aspects of crystallography, in particular supporting innovations in teaching and providing a platform for the relations of crystallography to other sciences.

\section{K. A. Kantardjieff, Chair (2009-2020)}

\subsection{Commission on Crystallography in Art and Cultural Heritage}

The Commission (CrysAC) continues to pursue the mission of spreading crystallographic knowledge related to artworks 
and ancient materials. In 2019 the Chair of the Commission Gilberto Artioli with Klaudia Hradil (from the organizing committee of the 32nd European Crystallographic Meeting, ECM32) prepared the 5th CrysAC Workshop on The Crystallography of Ancient Metals and Metal Corrosion (https:// ecm2019.org/satellites/crysac/). It was held in Vienna on 17 August 2019.

During the workshop, members of the CrysAC Commission (Gilberto Artioli, Petr Bezdicka, Elena Thereschenko and Alicja Rafalska-Lasocha) discussed the activities of the Commission for 2020: microsymposia that CrysAC will be involved in during the IUCr Congress in Prague; candidates for CrysAC membership for the term 2020-2023; and some issues concerning the cooperation of CrysAC members in educational processes at European universities.

Conferences, sessions, lectures, books: In May 2019, JoseMiguel Delgado and Petr Bezdička participated in the meeting the Current Trends and Future of Crystallography in Chemistry, Physics, Biology and Materials Science as representatives of the CrysAC Commission. This workshop was organized to prepare the scientific programme of the 25th General Assembly and Congress of the IUCr in August 2020 in Prague. As a result, it was decided that the CrysAC Commission will organize (1) or co-organize (2) the following microsymposia at the 25th IUCr Congress: Global Cultural Heritage Challenges and Crystallography: Where Do We Stand?, co-chaired by Dr Alicja Rafalska-Łasocha; X-ray Spectrometry and X-ray Diffraction in Art and Archaeology, co-chaired by Dr Petr Bezdička; and Science meets Art: Crystallography and Cultural Heritage.

Dr Elena Thereschenko delivered a seminar on 'The principle of the sciences convergence in the museum practice' in the framework of the International Festival 'Intermuseum' (May 2019, Moscow, Russia).

Professor Gilberto Artioli delivered a seminar on 'Blue colour from lapis lazuli to Klein' at the open workshop Colour in Science, Dipartimento di Beni Culturali, Università di Padova (June 2019), and delivered an invited talk at the Mineralogical Society of America Centennial (1919-2019) Symposium on 'Modern mineralogy and ancient pots: The archaeometry of ceramics' (Carnegie Institution for Science Building, Washington, DC, 20-21 June 2019).

In July 2019, Elena Thereschenko organized a microsymposium on Natural Sciences for the Study of Cultural Heritage in the framework of the 7th European Conference on Neutron Scattering, ECNS 2019 (St Petersburg, Russia).

Professor Koen Janssens (University of Antwerp, Belgium) delivered a public lecture during the ECM32 in Vienna, 'Examining old paintings with new X-ray methods: A fresh look at and below the surface'.

In September 2019, Dr Petr Bezdička attended the Jahrestagung 'Archäometrie und Denkmalpflege 2019' AK Archäometrie der GDCh in Vienna, Austria, and presented an invited talk 'The role of laboratory X-ray diffraction techniques in the provenance analysis of historical paintings', and took part in the organization of 7th interdisciplinary ALMA conference The Colour Theme, which focused on research, technology, history and conservation/restoration of fine art, Bratislava, Slovakia, 16-18 October 2019 (https://www.almalab.cz/userfiles/files/ALMA_2019_Preliminary_Programme. pdf).

Dr Elena Thereschenko chaired the session 'Interdisciplinary research and natural history research: new opportunities for historians' at the 1st International St Petersburg Historical Forum (October 2019, St Petersburg, Russia).

Professor Gilberto Artioli contributed a chapter Powder diffraction in art and archaeology to International Tables for Crystallography, Volume H, Powder Diffraction (https://it. iucr.org/Ha/, ISBN: 978-1-118-41628-0).

CrysAC website. The Commission is responsible for updating the CrysAC website at http://www.iucr.org/resources/ commissions/crysac.

Gilberto Artioli, Chair, and Alicja Rafalska-Lasocha, Past Secretary

\subsection{Commission on Crystallography of Materials}

The Commission website can be found at https://www. iucr.org/iucr/commissions/crystallography-of-materials. The members are Changqing Jin (Chair, China), B. Albert (Germany), E. Antipov (Russia), Wenhui Duan (China), V. Blatov (Russia), M. Eremets (Germany), Y. Gogotsi (USA) and M. Petrukhina (USA). The consultants are Tian Cui (China), V. L. Solozhenko (France), A. R. Oganov (Russia/ USA), H. Maynard-Casely (Australia), O. Yaghi (USA), S. Qiu (China), Nan Zhang (China) and Y. Sugawara (Japan).

Organizing conferences and symposia. Artem Oganov organized the Workshop on Crystal Structure Prediction: Exploring the Mendeleev Table as a Palette to Design New Materials (Grignano, Trieste, Italy, 14-18 January 2019), which had around 60 participants, and the 17th USPEX Workshop (Rennes, France, 4-6 July 2019), with around 70 participants. Changqing Jin organized one of the Symposiums of China Materials Research Society (Chengdu, China, 10-14 July 2019), see https://cmc2019.medmeeting.org/newsinfo/23414, with around 80 participants.

Disseminating knowledge and technical skills. Artem Oganov organized the Computational Materials Science Program of Excellence (Skoltech, Moscow, Russia, 7-8 September 2019), with around 70 participants.

\section{Plenary, keynote and invited lectures}

Artem Oganov: 'Artificial intelligence methods for probing matter at extreme conditions', 27th International Conference on High Pressure Science and Technology (AIRAPT27), 4-9 August 2019, Rio de Janeiro, Brazil;

Yury Gogotsi: 6th International Conference on Multifunctional, Hybrid and Nanomaterials, 12-14 March 2019, Sitges, Spain; 2nd International Conference on Mxenes, 10-12 May 2019, Beijing, China; International Symposium on Enhanced Electrochemical Capacitors, ISEECap2019, 5-8 May 2019, Nantes, France; NANO KOREA, 2-4 July 2019, South Korea; Graphene Week, 23-27 September 2019, 
Helsinki, Finland; Congress of the Mexican Carbon Association, 5 November 2019, San Luis Potosi, Mexico; and 2nd International Conference on Nanoscience and Nanotechnology, 29 November - 1 December 2019, Vellore Institute of Technology, India.

C. Q. Jin: 'New emergent materials at high pressures energy scale', 27th International Conference on High Pressure Science and Technology (AIRAPT27), 4-9 August 2019, Rio de Janeiro, Brazil; 'New high Tc cuprate superconductor with unique features', International Symposium on Frontier of Superconductivity Research (VIII): Advances in Exploration of Novel Superconductors, 24-27 October 2019, Beijing, China; 'Recent progress on materials sciences at extreme conditions', International Workshop: Current Trends and Future of Crystallography in Chemistry, Physics, Biology and Materials Sciences, 13-17 May 2019, Prague, Czech Republic; 'The cuprate superconductor with unique compressed local octahedron', MiniWorkshop of New Superconducting Materials, 15-17 April 2019, Donguan, Guangdong, China; 'Superconductivity in the unique type of copper oxide', the 17th Beijing Forum on High Temperature Superconductivity, 27-31 May, Zhangye, Gansu, China; and 'A new type cuprate superconductor with unconventional feature', the Chinese Physics Society Meeting, 19-22 September, Zhengzhou, Henan, China.

\section{Proposals for microsymposia for the IUCr Congress}

One of most important tasks for the Commission in 2019 was to propose microsymposia for the IUCr Congress to be held in Prague. We spend lots of time collecting ideas, discussing them and coordinating with our community on topics either suggested by our commission ( 9 in total) or to be sponsored jointly with other commissions (8 in total). Our commission proposed 9 microsymposia (6 approved including joint with other commissions) to the IUCr Congress:

Hydrogen Rich Compounds: Design, Properties and Phase Transitions at High Pressure (keywords: new structures, metallization, high pressure phase). Chair: Professor Alex Goncharov (Carnegie Institution Washington); Co-Chair: Artem Oganov (Skolkovo Institute of Science and Technology). (Joint with the Commission on Synchrotron and XFEL Radiation.)

The MXene Materials from Concepts to Applications. Chair: Vadym Mochalin (Missouri Tech, USA). (Joint with the Commission on Crystal Growth and Characterization of Materials.)

Quantum Emergent Materials (keywords: superconductors; diluted magnetic semiconductors; multiferroics). Chair: Changqing Jin; Co-Chair: S. Uchida. (Joint with the Commission on Neutron Scattering.)

Topological Materials: Prediction, Synthesis, Characterizations (keywords: topological insulators, Weyl semimetals, Majorana fermion materials). Chair: Professor W. H. Duan; Co-Chair: Professor Y. G. Yao (Beijing Institute of Technology). (Joint with the Commission on Quantum Crystallography.)

Superhard Materials: Status and Prospects (keywords: boronitrides, diamonds, nitrides). Chair: Professor Solozhenko
(Université Paris Nord). (Joint with the Commission on High Pressure.)

Materials of Low-Dimensional Crystal Structures (keywords: chains, 2D, spin liquids). Chair: Richard Hennig (University of Florida, USA). (Joint with the Commission on Magnetic Structures).

Nanocrystalline Materials (keywords: clusters, graphene, silicane). Chair: Professor Petrukhina; Co-Chair: Professor J. L. Zhu (South China University of Technology). (Joint with the Commission on Electron Crystallography.)

Energy Materials (keywords: perovskite solar cells, piezoelectric materials, energy transformations). Chair: Professor E. Antipov; Co-Chair: Yongsheng Hu (Institute of Physics CAS). (Joint with the Commission on Structural Chemistry.)

Crystal Structure Prediction (keywords: programs, iron compounds, oxides). Chair: Qiang Zhu (UNLV); Co-Chair: Rajeev Ahuja (Uppsala University Sweden). (Joint with the Commission on Crystallographic Computing.)

Changqing Jin, Chair

\subsection{Commission on Electron Crystallography}

The major goals of the Commission on Electron Crystallography (CEC) are the teaching and promotion of electron crystallography science. Members and consultants of the CEC take part in and organize a wide variety of activities in striving to achieve these goals. This year we report three types of activities: a special issue on electron crystallography, published in Acta Crystallographica Section B; workshops/ schools on electron crystallography, which are held all over the world, including India, the USA, Brazil, the UK, Norway and the Czech Republic; and plenary lectures on electron crystallography given at various conferences by members of the CEC. It should be noted that in the last year a major increase in the number of publications in our field was noted and interest in electron crystallography as a tool for structure solution of any type of crystal (inorganic, organic and biological matter) has risen.

Publication of a special issue on electron crystallography. In August 2019, Acta Crystallographica Section B published a special issue on electron crystallography containing reviews and novel original papers (https:/journals.iucr.org/b/issues/ 2019/04/00/). This issue's Guest Editors were Professor Joke Hadermann and Professor Lukas Palatinus, who are active members of the CEC and the IUCr. Most of the CEC members and consultants published articles in this issue.

Workshops/schools on electron crystallography. At the Microscopy and Microanalysis 2019 conference held in Portland, USA, in August 2019, the X-13 workshop titled Modern Electron Crystallography for Materials Sciences and Biology was organized by Professor Sergei Rouvimov, Professor Roberto Reis and Professor Peter Moeck (member of the CEC). Major topics covered in the workshop were: recent developments in electron crystallography for nanomaterials, including soft and biological materials; basics of scanning electron diffraction methods for microstructure analysis, including bio-crystals; electron crystallography applications 
for structural biology, including protein crystals; cryo-electron crystallography, including single-particle cryo-EM; and new experimental and computer-simulation techniques to improve the speed and reliability of structure characterization. Approximately 50 participants attended the workshop (https://www.microscopy.org/MandM/2019/program/short_ courses.cfm).

Professor Xiaodong Zou (member/consultant of the CEC) and Dr Hongyi Xu [member of SIG4 on electron crystallography of the European Crystallographic Association (ECA)] gave lectures at the eBIC MicroED Workshop at the Diamond Light Source, UK, 6-8 November 2019. There were around 30 participants (https://www.diamond.ac.uk/Home/ Events/2019/MicroED.html).

Dr Tom Willhammar and Dr Hongyi Xu (members of SIG4 on electron crystallography of the ECA) gave lectures at the Electron Diffraction Workshop at the NTNU in Trondheim, Norway, 15-16 May 2019, with 20-30 participants (https:// www.ntnu.edu/web/temgemini/diffraction2019).

Professor Karla Balzuweit (member of the CEC) organized the 1st Electron Crystallography School, 14-17 January 2019, at the Universidade Federal de Minas Gerais, Brazil. The school had 31 attendees. Lectures were given by CEC members and Dr Andy Stewart, consultant of the CEC.

Professor Lukas Palatinus (member of the CEC) organized the 37th ad hoc workshop on Jana2006 - Electron Diffraction, on data processing and structure refinement using electron diffraction data, 2-3 December 2019, at the Institute of Physics, Prague, Czech Republic. The workshop had 20 attendees. He also gave lectures at the GIAN workshop Structure Solution, Refinement and Interpretation of Difficult Inorganic Structures by Jana2006, an intensive course on structure analysis of inorganic materials, organized by Professor Partha Pratim Jana at the Indian Institute of Technology, Kharagpur, India. One day was dedicated to lectures and practical sessions on electron diffraction. The workshop had more than 10 attendees.

Plenary lectures on electron crystallography. A plenary lecture was given by Professor Xiaodong Zou (member/ consultant of the CEC) on electron crystallography at the 27th Annual Meeting of the German Crystallographic Society, 2528 March 2019, Leipzig, Germany.

Professor Lukas Palatinus (member of the CEC) gave a plenary lecture titled 'Structure determination by electron diffraction from single nanocrystals' at the European Conference on Solid State Chemistry, 1-4 September 2019, in Lille, France.

Louisa Meshi, Chair

\subsection{Commission on High Pressure}

Since not all the IUCr Commission on High Pressure (CHP) committee members attended the 2019 IUCr workshop in Vienna, Austria, we scheduled an informal meeting during the AIRAPT Conference in Rio, Brazil, on 6 August 2019. Six CHP committee members, Haozhe Liu, Kamil Dziubek, Guoyin Shen, Jean-Paul Itie, Narcizo Souza-Neto and Andrzej
Katrusiak, met and briefly exchanged ideas for the future workshop bidding situation and selection rules, workshop topics and highlights, a new CHP website, commission activities for the next IUCr General Assembly in Prague etc.

The 2019 workshop of the IUCr Commission on High Pressure took place in Vienna, Austria, 13-17 August 2019. The Chair of the Local Organizing Committee was Professor Ronald Miletich-Pawliczek from the University of Vienna, who was one of the local hosts for the 32nd European Crystallographic Meeting (ECM, 18-23 August 2019). This was the first time a back-to-back style arrangement for the CHP workshop, right before the ECM, had been tried. Workshop participants had opportunities to join talks and lectures in other satellite workshops in the same building (the Faculty of Electrical Engineering and Information Technology, Vienna Technical University). This workshop was jointly organized by the CHP (chaired by Haozhe Liu) and the European Crystallographic Association (ECA) Special Interest Group SIG-11 (chaired by Dr Yaroslav Filinchuk). We applied for travel funding from the IUCr, and this enabled us to support ten young early-stage scientists and students from seven countries all over the world.

This workshop event was attended by over 50 participants from 15 countries and regions, and included three full days of programme, organized into nine scientific sessions and featuring a total of 35 talks. Plenary talks were presented by Dr Eva Zurek (State University of New York at Buffalo, USA), Dr Stewart McWilliams (University of Edinburgh, UK) and Dr Takanori Hattori (J-PARC Center, Japan). The poster session featured 11 short lighting talks right before the poster presentations.

A special session titled 'Women under High Pressure' was added to the formal agenda, and many participants expressed support for this during the discussions.

Five CHP committee members (Haozhe Liu, Kamil Dziubek, Amy Lazicki, Boris Zakharov and Yasuo Ohishi) attended this workshop and acted as session conveners or session chairs. Haozhe Liu briefly introduced the history of the IUCr CHP workshop over the last two decades at the opening and closing sessions of this workshop. Those CHP committee members who were present met to discuss future workshop bidding, updating and maintenance of the website etc.

After deep discussions within the committee members who were at the meeting and some communications with other committee members through e-mails, the CHP committee voted and chose next year's workshop location as Novosibirsk, Russia, scheduled for the spring of 2020. The Local Organizing Committee will be led by Professor Elena Boldyreva from Novosibirsk State University and the Boreskov Institute of Catalysis in the Siberian Branch of Russian Academy of Science. Professor Boldyreva is a former CHP committee member and a former IUCr Executive Committee member (2008-2014).

CHP committee member Dr Narcizo Souza-Neto organized a workshop PRESSYNC: Synchrotron Techniques under High Pressure, 31 July - 2 August 2019, at the Brazilian Synchrotron Light Laboratory, Campinas, Brazil. CHP committee members 
Haozhe Liu, Kamil Dziubek and Jean-Paul Itie joined this workshop and delivered invited talks. At the end of this workshop, the local organizers hosted a facility tour of the high-pressure lab and the dedicated high-pressure beamline at Sirius, the new Brazilian synchrotron light source.

Acting as the representative for the CHP, Haozhe Liu attended the workshop Current Trends and Future of Crystallography in Chemistry, Physics, Biology and Materials Science in Prague, Czech Republic, 14-16 May 2019. This workshop was organized by the International Programme Committee to prepare for the 25th Congress of the IUCr, and summarized the main topics of modern crystallography represented by every commission of the IUCr. The talk was later published as Kamil Dziubek, Luhong Wang \& Haozhe Liu (2019). Towards the denser, hotter, faster and brighter future: challenges and opportunities of high-pressure crystallography. Materials Structure, 26, 91-93.

After this workshop, Haozhe Liu visited the local university, hosted by Professor Radek Kuzel. Professor Kuzel gave a guided tour of the X-ray labs and Dr Jiri Prchal's highpressure lab in the Department of Condensed Matter Physics, Charles University.

The previous website for the CHP had been set up and maintained by colleagues in the Edinburgh group on their local web server, which was officially closed down in 2019. We would like to thank Dr Ingo Loa again for his great work taking care of that website over the years. As suggested by the IUCr Executive Committee, the current CHP website has been set up on the IUCr web server at https://www.iucr.org/ resources/commissions/high-pressure. This new website was updated and launched in the summer of 2019. The Secretary of the CHP, Dr Kamil Dziubek, is acting as webmaster.

Haozhe Liu, Chair

\subsection{Commission on Inorganic and Mineral Structures}

Members and consultants of the IUCr Commission on Inorganic and Mineral Structures (CIMS) discussed various issues via e-mail. Other forms of communication took place through participation at occasional meetings or conferences.

The CIMS website is kindly maintained by M. Nespolo (CIMS member) at http://www.crystallography.fr/cims/.

The IUCr Commission on Structural Chemistry (CSC) and CIMS maintained their links. P. Mercier (CIMS Chair) is the liaison person representing the CSC on CIMS and vice versa.

CIMS also maintains strong links with the new IUCr Commission on NMR Crystallography \& Related Methods. J. Rocha (CIMS consultant) is the liaison person and also consultant for that commission.

P. Mercier (CIMS Chair) continues to act as liaison officer of CIMS with the IUCr Newsletter.

Strong links remain between CIMS and the European Crystallographic Association. Marie Colmont (CIMS member) is Chair of the Special Interest Group SIG5, Sergey Krivovichev (CIMS consultant) is Vice-Chair and Oleg Siidra is Secretary. The activities of SIG5 in 2018-2019 are listed at https://ecanews.org/wp-content/uploads/2019/08/ Report-SIG5_2019.pdf.

There are very good relationships between CIMS and the European Mineralogical Union (EMU, http://eurominunion. org/); R. Oberti (CIMS member) is Commissioning Editor of the EMU Notes in Mineralogy, which also implies scouting for the EMU schools.

M. Nespolo (CIMS member) is Book Review Editor for IUCr Journals, a member of the IUCr/OUP Selection Committee, Editor-in-chief of the SpringerBriefs series in Crystallography, and consultant on two IUCr commissions (Crystallographic Nomenclature; and Mathematical and Theoretical Crystallography).

In 2019 C. Ling (CIMS member) was President of the Society of Crystallographers in Australia and New Zealand (SCANZ) and Past Secretary of the Asia-Oceania Neutron Scattering Association (AONSA). He was Chair of Crystal-33, the 33rd meeting of SCANZ, held in early 2020 . He is a member of the Australian Synchrotron's User Advisory Committee and BRIGHT Advisory Committee, and a member of the Australian National Committee for Crystallography (ANCCr).

P. Mercier (CIMS Chair) was Chair of the Canadian National Committee for Crystallography between August 2015 and December 2019.

R. Oberti (CIMS member) was elected Corresponding Member of the Accademia Nazionale dei Lincei in Rome. She is a member of the committee on the participation of the CNR (Consiglio Nazionale delle Ricerche) to the IUCr. She was also member of the scientific committee for the 2019 EMU School Naturally Occurring Asbestos (NOA): From Geological to Medical Aspects, Casale Monferrato, Italy, 9-13 September 2019.

Frédéric Hatert (CIMS member) was a representative for ECM32 (https://ecm2019.org/home/). Marie Colmont (CIMS member) was a session Chair, and Sergey V. Krivovichev (CIMS consultant) was a Co-Chair.

P. Mercier (CIMS) represented CIMS interests at the International Programme Committee meeting for the IUCr Congress held in May 2019 in Prague, Czech Republic.

Members and consultants. The current list of CIMS members is P. Mercier (Chair, Canada), P. C. Burns (USA) (resigned February 2019), M. Colmont (France), F. Hatert (Belgium), V. Kahlenberg (Austria), M. Nespolo (France), R. Oberti (Italy), M. Wolcyrz (Poland), A. Yoshiasa (Japan) (resigned February 2019) and N. Zubkova (Russia). During January and February 2019, CIMS members had several e-mail discussions about proposing new members for the next triennium (2020-2023). The candidates included some of the current members and consultants, as well as nominations from National Committees communicated to CIMS by the IUCr Executive Secretary. A gender-balanced list of candidates was achieved. It is understood that a Chair shall be elected among the new members, either prior to or at the next IUCr Congress, which has been rescheduled to take place in 2021.

The current consultants are C. Cahill (USA), G. Ferraris (Italy), J. B. Parise (USA), I. Pignatelli (France), D. Pandey 
(India), S. V. Krivovichev (Russia), K. Byrappa (India), J. Rocha (past Chair, Portugal), R. Carbonio (Argentina), T. Gesing (Germany), C. Ling (Australia) and M. Welch (UK). The list will be revised prior to the next IUCr Congress. R. Oberti (Italy) has indicated her interest to remain active in CIMS as a consultant.

CIMS supported the application for funding by the IUCr of the following meetings held in 2019:

American Crystallographic Association Annual Meeting 2019, 20-24 July 2019, Covington, Kentucky, USA.

XIX International Meeting on Crystal Chemistry, X-ray Diffraction and Spectroscopy of Minerals, 2-5 July 2019, Apatity, Russia.

17th European Conference on Solid State Chemistry (https://ecssc17.com/), 1-4 September 2019, Université de Lille, France.

17th European Powder Diffraction Conference (EPDIC17), (https://www.epdic17.org/), 26-30 May 2019, Šibenik, Croatia.

Patrick H. J. Mercier, Chair

\subsection{Commission on Magnetic Structures}

The Commission was busy in 2019 in its effort to disseminate standards for the determination and communication of magnetic structures. Key activities include organizing and executing a ten-day school on magnetic crystallography, organizing sessions relevant to magnetic structure research for the programme of the upcoming IUCr Congress, and developing features to support magnetic structures in widely used crystallographic software.

53rd International School of Crystallography. The Commission organized and conducted the 53rd course of the International School of Crystallography at the Ettore Majorana Research Foundation in Erice, Italy, on the subject of Magnetic Crystallography (https://crystalerice.org/2019/ welcome.php), 31 May - 9 June 2019.

Commission members who participated in organization and/or lectures and workshops: Branton Campbell (Brigham Young University, USA), Maria Teresa Fernandez-Diaz (Institut Laue-Langevin, France) and Manuel Perez-Mato (Unversidad del Pais Vasco, Spain) (Science Directors); Maxim Avdeev (ANSTO Australian Center for Neutron Scattering, Australia), Ovidiu Garlea (ORNL Neutron Scattering Division, Oak Ridge, USA), Margarida Henriques (CAS Institute of Physics, Prague, Czech Republic), Vaclav Petricek (CAS Institute of Physics, Prague, Czech Republic), Juan Rodriguez-Carvajal (Institut Laue-Langevin, Grenoble, France), Taku Sato (Tohoku University, Tohoku, Japan), Andrew Wills (University College London, London, UK) and Oksana Zaharko (Paul Scherrer Institut, Villigen, Switzerland). Others who contributed lecture and workshop presentations: Laurent Chapon (Diamond Light Source, Didcot, UK), Luis Elcoro (University of the Basque Country, Bilbao, Spain), Oscar Fabelo (Institut Laue-Langevin, Grenoble, France), Dmitry Khalyavin (RAL ISIS Facility, Didcot, UK), Harold Stokes (Brigham Young University, Provo, USA) and Robert Von Dreele (ANL Advanced Photon Source,
Argonne, USA). The local organizing team was led by Annalisa Guerri (University of Florence, Italy) and Paola Spadon (University of Padova, Italy), and included computing and technical support from Andrea Giaccherini (University of Florence, Italy), Andy Stewart (University of Limerick, Ireland) and Erin Davis (USA).

The school was advertised internationally, with a special emphasis on reaching out to researchers in countries that are not typically well represented at such meetings. There were no restrictions on geographical affiliations of the participants. From among the roughly 100 applicants, 64 participants (not including the presenters) were selected based on their preparation and ability to benefit from attendance; this was the maximum number that facility-space limitations allowed. The participants and presenters came from 25 different nationalities and country affiliations, more than half of which were outside of Western Europe or North America. There were significant numbers from each of Russia and Eastern Europe, Asia, South America, and India. More than one third of the attendees were women.

The magnetic crystallography programme was organized to address key advances in magnetic structure research, as well as the foundational and state-of-the-art theoretical, experimental and computational capabilities that made these advances possible. The school included a roughly 50/50 combination of lectures and hands-on workshops. Three hours of workshops were held each morning, with two sessions conducted in parallel. The state-of-the art computational tools represented in the workshops included FullProf, JANA 2006, SARAh, the Bilbao Crystallographic Server, the ISOTROPY Software Suite, GSAS-II and TOPAS. Both introductory and advanced tutorial exercises were provided, in order to fully engage beginners and experts alike. Three hours of lectures were presented each afternoon. Topics included the experimental determination and communication of magnetic structures, the theoretical and mathematical foundations of magnetic symmetry and representational analysis, and a wide variety of applications. Each of the 17 presenters, in addition to contributing a lecture, also provided lecture notes in manuscript form. The technical programme ended with a one-hour panel discussion of questions submitted by the participants.

Of 40 submitted participant abstracts, ten were selected for oral presentations (22 minutes or 15 minutes), including Shivani Sharma (JNCASR, Bengaluru, India), Anna Matveeva (Petersburg Nuclear Physics Institute, Gatchina, Russia), Jose Luis Garcia-Munoz (ICMAB-CSIC, Barcelona, Spain), Stephanie Gneuwuch (University of Maryland, USA), Anuradha Vibhakar (University of Oxford, UK), Elena Solana Madruga (University of Edinburgh, UK), Stefanie Siebeneichler (Stockholm University, Sweden), Fernando Pomiro (University of Warwick, UK), Claire Colin (Institut Néel, Université Grenoble-Alpes, France) and Francoise Damay (Laboratoire Léon Brillouin, Gif-sur-Yvette, France). The two poster sessions for participant research were also of very high quality and were well attended during the school. Three of these posters were selected by a panel of judges for awards, which were presented during the closing ceremony, 
which included Premakumar Yanda (JNCASR, Bengaluru, India), Rebecca Scatena (University of Bern, Switzerland) and Guru Khalsa (Cornell University, USA).

To facilitate interaction between and among the participants and presenters, the school included a rich social programme. In the relaxed atmosphere, the organizers attempted to become personally acquainted with each participant. We are confident that the school initiated many longterm friendships and collaborations.

Preparations for the IUCr Congress. In preparation for the upcoming IUCr Congress in Prague, the Commission met online to brainstorm, select and prioritize potential topics. Oksana Zaharko, our representative to the International Programme Committee (IPC), travelled to Prague in May 2019 to negotiate the final programme. Her outstanding efforts and negotiation skills made it possible to organize 15 sessions with magnetic structure themes or components, among which nine microsymposia and three keynote lectures were sponsored or co-sponsored by the Commission:

Magnetic structures of novel and functional materials (MS30);

Structural, electronic and magnetic ordering: from fundamental physics to functionality (MS-38);

New applications of coherent scattering (MS-40);

Frustrated magnetic order and emerging science (MS-45);

Molecular magnets and metal-organic frameworks, including quantum crystallography approaches (MS-51);

Magnetic structures at extreme conditions and in extreme samples (MS-61);

Symmetry aspects of magnetic order and magnetic properties (MS-68);

Methods and software developments for magnetic structure analysis (MS-79);

Topological magnetic order and quasiparticles (MS-87);

'The science of symmetry breaking' (Harold Stokes, $\mathrm{KN}-35$ );

'Structural flexibility and disorder in functional materials' (Andrew Goodwin, KN-3); and

'Quantum crystallography and spintronic materials' (Piero Macchi, KN-15).

Oksana's invaluable service on the IPC is greatly appreciated by all. For the IPC meeting in Prague, Oksana, together with B. J. Campbell, J. M. Perez-Mato and T. Sato, submitted a manuscript on Magnetic structure research, future and future trends (http://www.xray.cz/ms/bul2019-2/cms.pdf), which was subsequently published in Materials Structure (2019), 26(2), 97-100.

Software development. The Bilbao Crystallographic Server upgraded the MTENSOR program to include magnetic phases, as reported in Acta Cryst. (2019), A75, 438-447 (https://doi.org/10.1107/S2053273319001748). It now calculates the symmetry-adapted forms of physical-property tensors that include magnetic properties. Also, over one hundred entries have been added to the MAGNDATA database of magnetic structures, bringing the total number to about 700 .

The first version of FullProf (version 7.00) able to refine magnetic structures (powder and single crystals) having up to three independent modulations within the superspace formalism was distributed in May 2019. The symmetry constraints on modulation functions were fully implemented for an arbitrary set of propagation vectors and harmonics. Spherical coordinates can be used to describe modulation amplitudes facilitating the use of extra constraints beyond symmetry. Presently, only magnetic modulations are available, though displacive, occupational and ADP modulations will be also implemented in the future. The program outputs a magnetic $P 1$-symmetry CIF file that can be directly read by VESTA to visualize a user-selected supercell. A conventional modulated mCIF file is also output with the refined magnetic structure. This file can be read by JMOL/MVISUALIZE to plot the magnetic structure.

Le Bail fits using superspace groups were also fully implemented in FullProf with an output adequate to perform, in a second stage, a simulated-annealing run working with the full powder profile to solve magnetic structures ab initio. All modulation functions are included in the simulated-annealing method with all kind of constraints compatible with the symmetry.

The program $m C I F_{-} t o \_P C R$ from the Bilbao Crystallographic Server has been extended to accommodate incommensurate structures with superspace-group symmetry. After importing a CIF from ISODISTORT, mCIF_to_PCR automatically allows one to prepare the input file for FullProf using a superspace group in whatever setting.

The program WinPLOTR-2006 in the FullProf suite has been modified in order to identify the different kinds of reflections: nuclear, magnetic or mixed (up to six integer indices), when using the superspace description.

$S A R A h$ was recently launched as a web application in order to stabilize its development base and move away from issues related to legacy Windows operating systems. As part of a goal to bring representational analysis calculations closer to the two-colour groups, the web version now determines isotropy groups and related magnetic point groups of the little group of the wavevector, and also determines the corresponding magnetic basis vectors, as well as those of the kernel calculations. Calculations can be done for commensurate and incommensurate structures alike.

$G S A S-I I$ now fully supports magnetic structures, including those with one incommensurate modulation. The search for a correct description of a magnetic structure is simplified in $G S A S-I I$ where a special version of the $k$-SUBGROUPSMAG tool from the Bilbao Crystallographic Server is called with the parent chemical space-group operations, selected $k$-vectors and some option flags. The result is parsed by $G S A S-I I$ to extract the generated magnetic space groups, transformation matrices, origin shift vector, conjugacy classes (if any) and supergroup lists. GSAS-II also examines the magnetic atom positions to determine if any or all can carry a nonzero moment, flagging those space groups with atoms that can.

$J A N A 2006$ performs representation analysis for $k=0$ and commensurate cases based on the irreducible representation data published by H. T. Stokes, B. J. Campbell and R. Cordes 
[Acta Cryst. (2013), A69, 388-395; https://doi.org/10.1107/ S0108767313007538]. This allows it to use the same symbols as in ISODISTORT. The procedure for importing the models from ISODISTORT was considerably improved. Furthermore, the new version allows parallel refinement of several models. The graphic interface for the new Jana2020 has also been further developed.

In the ISOTROPY Software Suite, the symmetry-allowed forms of Wyckoff sites are now presented for magnetic and non-magnetic incommensurate structures. Magnetic and nonmagnetic incommensurate symmetry groups have been partially implemented in FINDSYM and ISOCIF. When finished, it will be possible to detect the actual or pseudo symmetry (with tolerances on atomic parameters and Fourier coefficients) of an incommensurate magnetic structure. The magnetic superspace groups (MSSGs) with up to three modulations have been fully enumerated. All modulationcapable software tools have been updated to detect/present the correct MSSG number and symbol.

Scientific meetings. The members of the Commission actively promote the presentation of high-quality research on magnetic structures at a broad variety of international conferences, workshops and schools. The Commission supports a variety of scientific meetings each year through formal sponsorship, and with its members and consultants participating in featured lecture presentations, workshop tutorials, organization and chairing of conference sessions, and the presentation of lecture courses. Highlights from 2019 include the following:

Current Trends and Future in Crystallography, satellite meeting of the IUCr International Programme Committee meeting, 14 May 2019, Prague Congress Centre, Praha, Czech Republic. (Presenter: O. Zaharko, manuscript authors: O. Zaharko, B. J. Campbell, J. M. Perez-Mato, T. Sato).

International School of Crystallography (53rd course) on Magnetic Crystallography, 31 May - 9 June 2019, Ettore Majorana Foundation and Centre, Erice, Sicily, Italy. Directly organized by the Commission. (Scientific Directors: B. Campbell, M. Fernandez-Diaz, M. Perez-Mato; Lecturers: M. Avdeev, O. Garlea, M. Henriques, V. Petricek, J. RodriguezCarvajal, T. Sato, A. Wills, O. Zaharko.)

Neutron Summer School, session on Magnetic Structure Determination from Neutron Powder Diffraction, 19-21 June 2019, Peking University, Beijing, China. (Lecturer: M. Avdeev.)

International School on Crystallographic Groups \& Their Representations, and the subsequent Workshop on Topological Insulators, 1-7 July 2019, International Center for Quantum and Molecular Structure, Shanghai University, Shanghai, China. (Organizer and Lecturer: M. Aroyo.)

American Crystallographic Association Meeting, 20-24 July 2019, Covington, Kentucky, USA. Session on Magnetic, Quantum, and Electronic Correlated Materials. Sponsored by the Commission. (Co-Chair: B. Campbell.)

32nd European Crystallographic Meeting, satellite workshop on Neutron Scattering and Imaging for Newcomers, 1417 August 2019, Vienna University of Technology and
University of Vienna, Vienna, Austria. (Lecturers: V. Pomja-

kushin, M. Henriques, V. Petricek.)

Workshop on Symmetry and Superspace Approach to Modulated Crystal Structures, Oak Ridge National Laboratory, USA, 23-24 October 2019. (Lecturers: M. Henriques, V. Petricek, B. Campbell.)

Workshop on Magnetic Structure Determination from Neutron Diffraction Data, 21-23 October 2019, Oak Ridge National Laboratory, USA. (Co-organizer and Lecturer: O. Garlea.)

Masters course on Neutron Diffraction on Functional and Magnetic Materials, October - December 2019, Ural Federal University, Ekaterinburg, Russia. (Organizer and Lecturer: A. Pirogov.)

37th Ad Hoc Workshop on Jana2006 on the topic of Magnetic Structures, 14-15 November 2019, Institute of Physics, Praha, Czech Republic. (Organizers and Lecturers: V. Petricek, M. Henriques.)

Asia-Oceania Neutron Scattering Conference, 16-19 November 2019, Kenting, Taiwan. (Organizers and Lecturers: M. Avdeev, T. Sato.)

11th School of the Argentinean Association of Crystallography on Structural and Magnetic Rietveld Refinement of X-ray and Neutron Diffraction, 18-22 November 2019, Bariloche, Argentina. Sponsored by the Commission and supported by an IUCr Visiting Professorship to O. Fabello. (Lecturers: O. Fabello, J. Rodriguez-Carvajal.)

Commission membership: Branton Campbell (Chair, USA), Maxim Avdeev (Australia), Maria Teresa Fernandez-Diaz (France), Ovidiu Garlea (USA), Margarida Henriques (Czech Republic), J. Manuel Perez-Mato (Spain), Juan RodriguezCarvajal (France), Taku Sato (Japan), Andrew Wills (UK) and Oksana Zaharko (Switzerland).

Commission consultants: Mois Aroyo (Spain), J. Campo (Spain), Danny Litvin (USA), Alexander Pirogov (Russia) and Wieslawa Sikora (Poland).

Branton Campbell, Chair

4.15. Commission on Mathematical and Theoretical Crystallography

The members of the Commission (MaThCryst) are D. Pandey (India), V. A. Blatov (Russia), D. Gratias (France), J. Hadermann (Belgium), G. McColm (USA), H. B. Napolitano (Brazil), R. Oishi-Tomiyasu (Japan), M. L. A. N. De Las Peñas (Philippines), Wei Ren (People's Republic of China), L. Suescun (Uruguay) and P. Zeiner (Malaysia), and the consultants are M. I. Aroyo (Spain), J.-G. Eon (Brazil), E. E. Rams (Cuba), S. Hyde (Australia), D. B. Litvin (USA), K. Momma (Japan), M. Nespolo (France), D. Pradhan (India), D. Proserpio (Italy), B. Souvignier (The Netherlands) and B. Stöger (Austria).

Communications among the members and consultants of the Commission took place via e-mail. These discussions were related to possible topics, venues and funding of future schools, workshops and satellite meetings, and other outreach activities. Discussions of lists of speakers and keynotes for the 
IUCr Congress in Prague were held by e-mail, moderated by the International Programme Committee representative for the Commission, Louise De Las Peñas.

The following five workshops or schools were organized by the MaThCryst Commission. Details of each one are given on the Commission's and the event's home pages. Members and consultants of the Commission serving as speakers in these events are noted.

2019 AMS Sectional Meeting - Special Session on Crystallographic and Highly Symmetric Structures, University of Florida, Gainesville, USA, 2-3 November 2019, http://www.crystallography.fr/mathcryst/ams2019.php, http:// www.ams.org/meetings/sectional/2264_progfull.html. Organizers: Milé Krajčevski and MaThCryst member Gregory McColm. Speakers: Ma. Louise Antonette N. De Las Peñas, Erica Flapan, Abdulmelik Mohammed, Margherita Maria Ferrari, Chaim Goodman-Strauss, Egon Schulte, Ileana Streinu, Martin Cramer Pedersen, Nathan C. Carter and Massimo Nespolo.

ECM32 XXXII European Crystallographic Meeting, MaThCryst Satellite Conference on Graph Theory and Modular Structures, Technische Universität Wien, Vienna, Austria, 18-23 August 2019, http://www.crystallography.fr/ mathcryst/wien2019.php. Organizers and Programme Committee: Bernd Souvignier, Massimo Nespolo, Berthold Stöger. Lecturers: Bernd Souvignier, Massimo Nespolo and Berthold Stöger, with oral contributions by participants Shelomo I. Ben-Abraham and Vitaliy Kurlin. There were 15 participants, of which four were from Austria and 11 from abroad.

Eighth Training Course on Symmetry and Group Theory, http://www.crystallography.fr/mathcryst/TrainingCourseJapan. php, Tsukuba, 22-26 July 2019 (English), 29 July - 2 August 2019 (Japanese), special session Mount Koya, 4-9 August 2019. Local Organizing Committee: Takashi Kamiyama, Noriyuki Igarashi and Yoshimi Takahashi. Speaker: Massimo Nespolo.

Second Shanghai International School on Crystallographic Groups and Representations, and Their Application in Magnetic Structure Descriptions and Topological-Insulator Studies, Shanghai University, Shanghai, 1-7 July 2019, http:// www.crystallography.fr/mathcryst/shanghai2019.php. Organizers: Mois Aroyo, A. Stroppa and W. Ren. Lecturers: Mois I. Aroyo, B. Andrei Bernevig, Barry Bradlyn, Jennifer Cano, Luis Elcoro, Massimo Nespolo and Bernd Souvignier. There were 110 participants from China and abroad, and all the lectures were broadcast live all around the world on the Koushare academic platform, a platform that aims to spread science widely by using new technologies. A total of 9854 people watched online via this platform.

Summer School on Mathematical Crystallography, Nancy, France, 3-7 June 2019, http://www.crystallography.fr/ mathcryst/nancy2019.php. Local Organizing Committee: Massimo Nespolo and Isabella Pignatelli. Lecturers: Massimo Nespolo, Benoit Guillot and Gemma de la Flor Martin; tutors: Isabella Pignatelli, Berthold Stöger and Valeri Richalet.

Mois Aroyo was a member of the Scientific and Programme Committee for the International Crystallography School
'Crystallographic Information Fiesta', Naples, Italy, 29 August - 3 September 2019 (organized by the Italian Crystallographic Association and supported by the IUCr). He gave a Plenary Lecture on 'Space-group symmetry - Understanding International Tables for Crystallography, Vol. A', a lecture on magnetic and incommensurate CIF extension dictionaries and a tutorial on Crystallography Online by the Bilbao Crystallographic Server.

Mois is also Editor of the 6th edition of Volume A (Spacegroup symmetry) of International Tables for Crystallography, published by the IUCr, and Editor of the 6th edition of the Teaching Edition of International Tables for Crystallography, to be published by the IUCr (in preparation). He is also responsible for the development of the Symmetry Database server of the Online Edition of International Tables for Crystallography (on the IUCr website).

Ma. Louise Antonette De Las Peñas is an International Programme Committee Member for the IUCr 2020 Congress (now moved to 14-22 August 2021). She attended the IPC meeting in Hotel Olsanka, Prague, 15-16 May 2019, to prepare the Congress programme and the list of keynote and invited speakers, and gave a talk on 'The future of mathematical crystallography' at the Workshop on Current Trends and Future of Crystallography in Chemistry, Physics, Biology and Materials Science, 14 May 2019, in the Prague Congress Center.

Hamilton Napolitano gave a talk on 'Structural analysis and biological profile of a novel hydroxychalcone' in the session Solid State Supramolecular Chemistry and Crystal Engineering Part II at the 2019 ACA Annual Meeting in Covington, Kentucky, USA, 20-24 July 2019.

Ma. Louise Antonette N. De Las Peñas, Secretary

\subsection{Commission on Neutron Scattering}

The Commission (CNS) promotes the use of neutron scattering by encouraging the publication of information on the capabilities of neutron sources and instrumentation and by supporting symposia, schools and workshops that educate researchers on the unique information that can be provided by neutron scattering. Several members of the Commission are actively involved in developing neutron sources and new neutron-scattering technologies and methods.

The operation of major neutron facilities has continued, except for temporary closures and/or suspensions for user operation in some facilities due to the COVID-19 pandemic.

The construction of the European Spallation Neutron Source (ESS) in Sweden is progressing. The launch of the first beam has been changed to 2023, and the user programme will be started in 2024 .

The Chinese Spallation Neutron Source (CSNS) started operation in August 2018 with three instruments (a powder diffractometer, a reflectometer and SANS).

The operation of J-PARC MLF in Japan is also continuing with $500 \mathrm{~kW}$ beam power, and the beam power will be upgraded in 2020. 
The Spallation Neutron Source (SNS) in the USA continued operation at $1.4 \mathrm{MW}$, providing more than 4500 neutron production hours annually. Eighteen instruments are currently available to the neutron-scattering community. Construction began on a time-of-flight neutron imaging instrument (VENUS), with commissioning anticipated in 2023. Preliminary design has begun for a diffractometer (DISCOVER) that combines the advantages of high- $Q$ resolution and wide $Q$-range time-of-flight neutron scattering with low and stable background to study real materials in their operating environments. Progress continues on the Proton Power Upgrade (PPU) project for SNS, which is now $25 \%$ complete. The PPU project will double the power capability of the SNS accelerator from 1.4 to $2.8 \mathrm{MW}$, to facilitate new types of experiments and discoveries. In addition to providing $40 \%$ more power to the existing SNS First Target Station (FTS) instruments, it will power a future Second Target Station (STS) to provide pulsed beams of 'cold' neutrons with high peak brightness that enable studies of more complex materials. STS will provide up to 22 new instruments.

The High Flux Isotope Reactor (HFIR) continued operation at $85 \mathrm{MW}$, providing more than 3900 neutron production hours annually. Twelve instruments are currently available to the neutron-scattering community. Plans are underway to expand the current HFIR cold guide hall and install a new neutron guide during the beryllium outage in 2024. Proposal calls for beam time at SNS and HFIR are held twice a year. Demand for neutrons at SNS and HFIR continued to remain high with subscription rates of $292 \%$ and $189 \%$, respectively.

At the Laboratoire Léon Brillouin (LLB) the Orphée reactor in Saclay (France) and at the Helmholtz Zentrum Berlin (HZB) the BER I reactor in Berlin (Germany) were both shut down at the end of 2019 while the large-scale facilities themselves stay active in current and future projects at other neutron facilities.

The Heinz Maier-Leibnitz Zentrum (MLZ) at the FRM II reactor in Garching near Munich has overcome a delivery problem that led to delays in the provision of beam time in 2019, and will continue standard operation from January 2020 on.

The League of Advanced European Neutron Sources (LENS) held its second General Assembly at the Institut Laue-Langevin (ILL) in October 2019 to define priority actions for the organization in the months to come. The EU project CREMLINplus (Connecting Russian and European Measures for Large-scale Research Infrastructures - plus) supports cooperation of large-scale facilities from the European Union and from Russia. The consortium contains 25 partners from the EU and associated countries, and 10 partners from Russia, including the neutron source PIK at Gatchina near St Petersburg and the ion-collider facility NICA in Dubna.

On 23 March the Australian Centre for Neutron Scattering (ACNS) at the OPAL source moved to an essential and critical operations mode and ACNS has had an open call for COVID19 related research using neutron-scattering instruments. Since then, the OPAL reactor continued to operate whilst the neutron-scattering instruments were shut down and ACNS staff are mainly working from home. Another direct impact of the COVID-19 pandemic was the postponement to June 2021 of the OPAL long shutdown that was scheduled to occur in June 2020.

Our commission members were also involved in organizing several meetings, not only for neutron but also for quantum beam (synchrotron, neutron and ion radiation etc.) joint use, that took place in 2019, including various annual meetings of regional crystallographic associations. The 3rd Asia-Oceania Conference on Neutron Scattering (AOCNS2019) was held at Kenting, Taiwan, 16-21 November with 313 participants from 18 countries. The European Conference on Neutron Scattering (ECNS2019, http://ecns2019.com/) took place in St Petersburg, Russia, 30 June - 7 July 2019, with 572 participants from 33 countries.

Several neutron schools at many facilities were supported by commission members. In Asia-Oceania region, the 4th Neutron and Muon School \& MIRAI PhD School 2019 was held at J-PARC in Japan, 28 October - 2 November, with 41 students from 12 countries. In India, a National Seminar on Crystallography was held 19-22 June 2019 at Bhabha Atomic Research Centre, Mumbai. The seminar emphasized the role of neutron scattering in crystallography. Around the 32nd European Crystallographic Meeting (ECM32) in Vienna, Austria, 18-23 August 2019, a four-day satellite workshop Neutron Scattering and Imaging for Newcomers was organized by a commission member jointly with colleagues from Switzerland and Austria, and attracted students from various countries around Europe. In the USA, SNS and HFIR staff partnered with a US light source to host a two-week Neutron and X-ray School (NXS) to introduce graduate students to $\mathrm{X}$-ray and neutron scattering techniques. Other schools that SNS and HFIR staff organize annually are the HFIR-SNS Advanced Neutron Diffraction and Scattering (HANDS) school, which introduces researchers with knowledge of the structure and function of biological macromolecules to neutron scattering; the US School on Total Scattering Analysis; and Magnetic Structure Determination from Neutron Diffraction Data. In 2020, these schools were made available to students through virtual classrooms. SNS staff also participate in the US Particle Accelerator School held twice a year. The school typically attracts more than 100 students each session.

Commission members were involved in planning activities for several important neutron conferences and schools in 2020. Owing to the COVID-19 pandemic, some conferences, meetings and schools have been postponed or changed to virtual events.

\section{T. Ishigaki, Chair}

4.17. Commission on NMR Crystallography and Related Methods

In this reporting period, our Commission is nearing the end of its second triennium. The bulk of the Commission's activities continues to involve work with regional crystallographic 
associations and helping to organize themed sessions on NMR crystallography at their annual meetings.

Connections between the Commission and the American Crystallographic Association (ACA) continue to strengthen. The ACA has been receptive to the Commission's activities and has welcomed efforts to organize themed sessions on NMR crystallography. Sessions on NMR crystallography have become regular features at the last three annual meetings of the ACA. The 2019 annual meeting of the ACA in Covington, Kentucky, USA (20-24 July 2019) featured a half-session on NMR crystallography, co-chaired by Tomislav Friscic and Manish Mehta. Three speakers were part of a programme representative of the NMR crystallography community in North America. They were Robert Schurko (University of Windsor, Canada, now at Florida State University, USA), Roderick Wasylishen (University of Alberta, Canada) and Aaron Rossini (Iowa State University, USA). The session enjoyed good attendance and delivered on the high expectations set by the previous year's session. The participants felt clear momentum coming out of the meeting, as well as a certain relevance to the larger crystallography community. In anticipation of the IUCr Congress in Prague in 2020, it was decided that there would be no session on NMR crystallography at the 2020 ACA meeting. The Commission had already planned to have a full session and a keynote on NMR crystallography at the Prague Congress. Collaborative efforts between our Commission and the ACA may serve as a model for connections with other regional crystallographic associations. The Commission has also supported SMARTER conferences.

Manish Mehta, Secretary

\subsection{Commission on Powder Diffraction}

Odd calendar years are generally quieter years, and 2019 was especially so as it immediately preceded a year that was scheduled for two major powder meetings, these being EPDIC17 in Croatia and the 25th Congress and General Assembly of the IUCr, both of which have now been rescheduled to 2021 owing to the COVID-19 pandemic. Professor Brendan Kennedy continues as the Commission on Powder Diffraction (CPD) representative on the International Programme Committee for the IUCr Congress.

In addition to the meetings above, the CPD also supported a number of smaller meetings. This included the EXPO\&more International Workshop, Bari, Italy; the II LACA School 2019, Colombia; To.Sca.Lake 3.0: Total Scattering for Nanotechnology on the Como Lake, Italy; and BCA2019, Hammamet, Tunisia.

A number of other meetings originally scheduled for 2020 were also supported.

Although most of the business of the CPD is conducted via e-mail communications, in-person meetings are planned for both the EPDIC meeting and the IUCr Congress.

Also of great significance to the CPD was the eventual publishing of Volume $\mathrm{H}$ of International Tables for Crystal- lography, and it is understood from Chester that approximately 150 copies have already been sold.

The CPD is also please to confirm that the 60th International School of Crystallography in Erice will be devoted to powder diffraction and has been scheduled for 31 May to 8 June 2024.

It has proven to be rather challenging to make progress with a number of projects. This is mostly owing to limited resources and the already high demands on their time from their primary employers experienced by most members. It might be worthwhile approaching some retired ex-members for this, possibly as commissioned work for which funding can be sought.

Ongoing CPD projects include the following.

Recommended Practice and Publication Guidelines. Most members are concerned about the poor quality of data published in many journals and the fact that this is generally exacerbated by poor reporting and/or poor interpretation of the data.

QPA Round Robin. After approximately 20 years, the Commission has decided to put together another quantitative phase analysis round robin, to assess the current state of this traditionally very important part of powder diffraction, particularly the impact that improved instrumentation, software and methodologies might have had on the field. The project will be coordinated by Dr Matthew Rowles from Curtin University in Australia. This is a considerable undertaking and will require the hiring of a temporary assistant. To cover this as well as the operational expenses, the CPD hopes to raise financial support from suppliers and other interested parties. Dr Rowles will put together a detailed project plan and budget.

PowderCIF project. It appears that this project has become dormant in the last triennium and it is necessary to reconsider an appropriate course of action once we have clarity of its current status.

It is hoped that the Recommended Practice and Publication Guidelines as well as the call for participants and the subsequent results from the QPA Round Robin will all be published in IUCr journals.

The Commission on Powder Diffraction maintains close links with the International Centre for Diffraction Data (ICDD), and has initiated discussions about how this relationship can possibly be developed into something more substantive and of mutual benefit.

\section{G. Billing, Chair}

\subsection{Commission on Quantum Crystallography}

Quantum crystallography (QCr) has now established itself as the discipline where quantum-mechanical methods and computational chemistry combine with $\mathrm{X}$-ray, neutron or electron scattering techniques to gain a better understanding of crystalline material properties.

In 2019, the QCr community has been very dynamic in conferences, papers and, thanks to $\mathrm{K}$. Wozniak, preparation for its significant involvement in the forthcoming $\mathrm{IUCr}$ 
Congress in Prague. Unfortunately, owing to the COVID-19 pandemic, the Prague meeting has been postponed to 2021.

Nevertheless, and more than ever, members of the Commission are still promoting quantum crystallography through the project led by P. Macchi (University of Milan, Italy), Establishing Quantum Crystallography. Our community will apply for an IUPAC project (tentatively) named Defining the Scope of Quantum Crystallography.

A workshop in Bremen (14-19 July 2019), chaired by S. Grabowsky (University of Bern, Switzerland) aimed at giving 'Tools for Chemical Bonding' from an electron-density perspective. A selection of software packages used in quantum chemistry and quantum crystallography were emphasized with hands-on sessions.

The International Charge Density Meeting (ICDM) was held 21-26 July 2019 in Göttingen, Germany. It was beautifully organized by D. Stalke (University of Göttingen). The next ICDM is expected to be organized by J. Overgaard (Aarhus University, Denmark) and colleagues in 2022, and will be held in Denmark.

We had a specific microsymposium on Modern Quantum Crystallography at the 2019 European Crystallography Meeting in Vienna. However, QCr was also represented and the results shown in several other microsymposiums. An important moment for us was the plenary lecture on $\mathrm{QCr}$ studies of advanced materials given by our colleague $\mathrm{B}$. Iversen from Aarhus University.

After the 2018 Sagamore meeting on Quantum Crystallography held in Halifax (chaired by C. Matta and P. Ayers) it was decided that the next meeting should be organized in 2021 by P. Munshi (IIS Bangalore) in India. However, it is unclear at this time whether scheduled meetings might be postponed by a year.

Another meeting worth mentioning was the Chitel/Quitel (in Montreal), which, unlike the meaning of the acronym (Theoretical Chemists of Latin Expression), was well attended by several members of the QCr community. It was an interesting way of connecting with experts in a large variety of theoretical techniques that are relevant to similar problems studied in quantum crystallography.

The recent decision to postpone the IUCr Congress led the Commission to organize a three-day online meeting. It is named QCrOM2020 (Quantum Crystallography Online Meeting). It turns out to be a unique opportunity to connect with researchers who usually do not participate in our conferences because of the costs (the meeting will have no registration fees) or the difficulty of travelling. Next year's commission report will include our conclusions on the pertinence of this initiative.

Jean-Michel Gillet, Chair

\subsection{Commission on Small-Angle Scattering}

The following report was prepared by U-Ser Jeng, Chair of the Commission on Small-Angle Scattering (CSAS), together with members David Babonneau, Kristina Djinovic Carugo,
Elliot Gilbert, Duncan McGillivray, Jan Ilavsky, Eleonora Shtykova, Masaaki Sugiyama and consultants Andrew Allen, Javier Pérez, Daniel Clemens, Pete Jemian, Jill Trewhella, Dmitri Svergun and Iris Torriani.

For 2019, the business of the Commission was conducted principally via e-mail and during personal meetings at national and international conferences. There was good engagement from many of the CSAS members and consultants. A summary of highlights of activities for calendar year 2019 follows.

Commission activities, meetings and communication

Elliot Gilbert served on the International Scientific Programme Committee for the Asia-Oceania Neutron Scattering Association Conference, Kenting, Taiwan, 17-21 November 2019.

Selected papers from the Neutrons and Food 5 conference held in Sydney in 2018, chaired and organized by Elliot Gilbert, were published in a special issue of the journal Food Structure in 2019 with the report for the meeting published in Neutron News (2019), 30:1, 5-8.

Jan Ilavsky organized a SAS workshop and SAS session at the 68th Annual Denver X-ray Conference, held as a joint meeting with the 25th International Congress on X-ray Optics and Microanalysis (ICXOM-25), Lombard, Illinois, USA, 5-9 August 2019.

Andrew Allen served as CSAS representative, throughout 2019, on the International Programme Committee (IPC) for the IUCr 2020 Congress, to be held in Prague, Czech Republic, now postponed to August 2021. He attended the IPC workshop, presenting a talk 'Current highlights \& future trends in small-angle scattering' and the planning meeting in Prague, May 2019, both as CSAS representative and as IUCr Journals Editor-in-chief. As CSAS representative he was able to negotiate several SAS-related microsymposia and a SASrelated keynote talk as part of the overall IUCr Congress programme.

U-Ser Jeng served on the International Scientific Programme Committee, organized/chaired two sessions, on Soft Matter Systems and on Fundamental Physics, and gave an invited talk for the Asia-Oceania Neutron Scattering Association Conference, Kenting, Taiwan, 17-21 November 2019.

U-Ser Jeng served as CSAS Chair, and recommended two IUCr2020 workshops on SAS and BioSAS organized by Jan Ilavsky and GISAXS-GIWAXS by Eva Herzig, R. Joseph Kline and U-Ser Jeng, and updated the CSAS website, including historical data about SAS conferences. He also wrote a letter to the organizers of the SAS-2021 triennial conference to say that CSAS recommends a postponement of the SAS-2021 triennial conference to 2022, to avoid competing with the rescheduled IUCr Congress and the possible continuation of conflicts between IUCr Congresses and SAS triennial meetings going forward.

\section{Educational activities}

Elliot Gilbert gave a keynote lecture on the application of scattering, particularly SANS, in food materials science, 'Food materials science and neutron scattering: current status and opportunities for the AONSA region', at the Asia-Oceania Neutron Scattering Association Conference, Kenting, Taiwan, 
17-21 November 2019. U-Ser Jeng also gave an invited talk at that meeting.

Elliot Gilbert wrote a review covering the last three years on SAS as applied to food in Small-angle X-ray and neutron scattering in food colloids [Current Opinion in Colloid \& Interface Science, (2019), 42, 55-72].

Jan Ilavsky organized a course Beyond Rg Materials in October 2019. This course was attended by 30 students and five lecturers. He also co-organized Beyond Rg Bio in August 2019, with 35 attendees and six lecturers. Both courses were staffed by APS SAXS Special Interest group members and are part of a series of Beyond Rg courses that have been held at the APS for more than ten years. He also organized an Irena and Nika course at the APS in May 2019 as a satellite meeting to the APS Users Meeting. Twenty-two students attended this two-day course.

Dmitri Svergun presented multiple lectures on small-angle scattering including:

'Small-angle scattering on macromolecular solutions: basics' and 'Small-angle scattering to study disorder and aggregation' at the ECOST Experimental Training School (7-11 January 2019, Masaryk University, Brno, Czech Republic);

'Small angle X-ray scattering from solutions of biological macromolecules using synchrotron radiation' at the DESY Photon Science Users' Meeting (25 January 2019, Hamburg, Germany);

Keynote lecture 'Small-angle X-ray scattering on macromolecular solutions: progress and perspectives' at the British Crystallographic Association meeting (16 April 2019, Nottingham, UK);

'Joint use of small-angle X-ray scattering with structural and biophysical methods to study enzyme structure and dynamics' at the Advanced Course on Trends in Enzymology and Biocatalysis (27-30 May 2019, Rome, Italy); and

'Development of analysis methods for scattering studies of biological systems' at the symposium Recent Progress in Small-Angle Scattering from Soft Matter and Biological Systems (18-19 June 2019, Aarhus, Denmark).

Jill Trewhella presented three lectures on SAXS, SANS and publication standards for small-angle scattering as part of the EMBO Global Exchange Lecture Course entitled Structural and Biophysical Methods for Biological Macromolecules in Solution, organized by Dmitri Svergun, 14-20 October 2019, Santiago, Chile.

U-Ser Jeng organized a one-day training course on SAXS measurements for the 3rd AOFSRR School, 3-9 November 2019, and a data-analysis tutorial workshop at the 24th (Taiwan) Biophysics Conference at the National Ilan University, Ilan, Taiwan, 29 May - 1 June 2019.

Community-building activities

Elliot Gilbert continues to serve as Co-editor for the Journal of Applied Crystallography and on the Editorial Board of Food Structure.

Approximately $40 \%$ of the content at the fifth international Neutrons and Food 5 conference in Sydney, chaired and organized by Elliot Gilbert, highlighted the application of small-angle scattering methods to investigate a diverse array of food materials. This is a relatively new but developing community.

Jan Ilavsky maintains the APS SAXS Special Interest Group page (https://small-angle.xray.aps.anl.gov).

Dmitri Svergun continued as a Co-editor of the Journal of Applied Crystallography and as a member of the Associate Editorial Board of Frontiers in Molecular Biosciences, section Structural Biology, and continued to act as a Management Committee member and Work package responsible for a panEuropean access grant iNEXT (completed in August 2019).

Jill Trewhella continued her community-building work with the biomolecular structure community. She was a co-organizer of Working Towards Federating Structural Models and Data, a satellite meeting at the Biophysical Society Annual Meeting held in Baltimore, 1 March 2019. The meeting was supported by the US National Science Foundation (NSF) and sponsored by the Worldwide Protein Data Bank (wwPDB). The participants came together to assess progress toward archiving integrative structures since the wwPDB-sponsored Integrative/Hybrid Methods (IHM) Task Force meeting held in 2014 at the European Bioinformatics Institute (EBI). The group was asked to make recommendations for next steps, including addressing the challenges of creating common data standards, building methods for federated data exchange, and developing mechanisms for validating integrative structures. Dmitri Svergun presented an update on his work on the SmallAngle Scattering Biological Data Bank, SASBDB, which has the capability to interoperate with model and data archives including the Protein Data Bank. Jill Trewhella and Dmitri Svergun contributed to the publications of the outcomes of the meeting [Berman et al. (2019), Structure, 27, 1745-1759] that included six recommendations addressing the needs for a standard dictionary of terms to facilitate data exchange between repositories, the development of common data standards, validation protocols that include measures of data quality and model fit to available data, communications with journal Editors regarding the new standards and databases, and advocating for support for the needed infrastructure required to archive integrative structures.

Jill Trewhella continued as a Co-editor (Biology and Medicine section) for $I U C r J$, as an Editorial Board member for Biophysical Journal and as an International Advisory Board member for Protein Science.

Andrew Allen served as Editor-in-chief of IUCr Journals. As such, he continued to encourage negotiations between the SAS 2021 Conference organization and IUCr Journals for an open-access special issue of the Journal of Applied Crystallography associated with the conference.

U-Ser Jeng served as a Co-editor for the Journal of Synchrotron Radiation. He also communicated with the SAS2021 organizer Dr Florian Edouard P. Meneau and the IUCr for a possible proceedings for the triennial conference SAS2021.

Consultant activities

Jan Ilavsky served as Chair of the beam-time proposal review committee for ORNL SANS instruments and has 
served as a reviewer for NIST SANS instruments as well as the SSRL SAXS instrument.

Jill Trewhella continued to serve as a member of the Worldwide Protein Data Bank Advisory Committee, providing expert input on small-angle scattering and its role in integrative/hybrid structure determination.

Dmitri Svergun continued to serve on the Scientific Advisory Committee of the National Synchrotron Radiation Research Center, Taiwan.

Andrew Allen continued to provide informal input for drafts for ISO standards on the use of small-angle scattering, specifically SAXS for particle characterization. Currently, some revision is underway for the existing ISO standard on particle-size determination using SAXS, and a new ISO standard is being drafted to cover surface-area measurement using SAXS methods. Between the revision and the new draft, the critical aspects of characterizing particle-size distribution (rather than just mean size), and particle shape, are now being actively addressed as key issues in relating surface-area measurements (using Porod scattering etc.) to particle size and volume fraction.

U-Ser Jeng continued to serve as a consultant member of the Physics Discipline of the Ministry of Science, Taiwan.

Organizational activities

Dmitri Svergun was the organizer of the EMBO-supported EMBO Global Exchange Lecture Course on Structural and Biophysical Methods for Biological Macromolecules in Solution (Santiago, Chile, 14-20 October 2019). The course was coorganized together with Professor Francisco Melo Ledermann (P. Universidad Católica de Chile), Al Kikhney (EMBL Hamburg) and Alejandro Panjkovich (Celgene Institute for Translational Research Europe). There were a total of 79 applications to the course, of which 33 were selected. Of these, 15 participants were from Chile, 7 from Argentina, 3 from Uruguay, 2 from Brazil, 1 from Mexico, 3 from Europe, 1 from Russia and 1 from the USA. Thirteen travel grants were given to participants from Latin America and Europe. All participants presented posters. Thirteen tutors (9 from Europe, 1 from Australia and 3 from Chile) and the Dean of the faculty of Biological Sciences of P. Universidad Católica de Chile contributed 28 lectures and 7 tutorial sessions covering a broad range of structural and biophysical techniques for characterization of biological macromolecules in solution. The course was held at the Biological Sciences Faculty of the Pontifical Catholic University of Chile and in the meeting room of the Hotel Neruda. During the fifth day of the course the civil protests escalated in Santiago, which lead to multiple acts of vandalism, a state of emergency was announced in Chile and the University was closed. A new lecture room was promptly organized in the Hotel Neruda where the students were staying (an area which was not affected by the protests). The tutors were relocated from the Hotel Cumbres Lastarria (close to the University, in the area affected by the protests) to the Hotel Neruda. Despite these unforeseen circumstances, the course was successfully completed and only a few lectures had to be shortened. Special attention was given to smallangle X-ray and neutron scattering (SAXS/SANS), cryo-EM, bioinformatics and to NMR spectroscopy, where introductory and advanced lectures were presented. For numerous other techniques (spectroscopy, hydrodynamic methods, light scattering, molecular dynamics) both European and local speakers explained the basics of the methods together with their applications. Several lectures towards the end of the course were specifically devoted to multidisciplinary research approaches and hybrid methods to demonstrate the advantages of combining techniques in modern biological research.

David Babonneau served as Chair of the Peer Review Committee 3: Matter and Material Properties: Structure, Organization and Characterization, Elaboration for beamtime allocation at the SOLEIL synchrotron, France.

\section{Technical activities}

Elliot Gilbert is beamline scientist for the QUOKKA SANS instrument at the OPAL facility in Australia and continues to have a focus on the development of novel sample environments to generate increased utilization and demand for SANS.

Jan Ilavsky is lead instrument scientist for the USAXS/ SAXS/WAXS instrument at Advanced Photon Source, ANL, USA. He also maintains software packages Irena and Nika used widely by the materials science SAS community for data reduction and analysis. He released one update to the package in 2019. The total combined number of unique installations in 2019 was over 1000.

The 2017 publication guidelines for structural modelling of small-angle scattering data from biomolecules in solution: an update by Jill Trewhella et al. continues to attract strong readership with over 9000 downloads, 60 Scopus citations, and increasing uptake of the recommended table and data deposition in the community. Dmitri Svergun is a co-author of this work.

Jill Trewhella, in her capacity as Chair of the Worldwide Protein Data Bank Small-Angle Scattering validation task force (SASvtf), is coordinating an initiative that aims to generate a set of SAS data sets that can be used to benchmark different approaches to predicting SAS profiles from atomic coordinates (see https://sas.wwpdb.org/?q=node/25 for full details and participants). The effort included CSAS consultants Javier Pérez, Dmitri Svergun and 33 SAS experts from across Europe, Asia and the Americas. During 2019, samples of five standard proteins with standard buffers were distributed to 12 SAXS facilities and four SANS facilities, and to date 236 data sets have been returned for analysis; including SEC-SAXS and batch SAXS, SEC-SANS and batch SANS in $\mathrm{H}_{2} \mathrm{O}$ and $\mathrm{D}_{2} \mathrm{O}$ with a range of concentrations for the batch measurements. The analysis so far shows a strong consensus in the results obtained in terms of overall conformational parameters, and at least a subset of the proteins measured are candidates for providing scattering profiles for benchmarking methods for SAS profile prediction.

Dmitri Svergun's group continued to maintain and curate the Small Angle Scattering Biological Data Bank (https:// www.sasbdb.org; main curators A. Kikhney and C. Jeffries), which presently contains over 1200 data sets and over 2000 models. The $A T S A S$ program package developed by the group is presently at version number 3.0, and, as of 2019, ATSAS has 
been downloaded over 100000 times and is utilized in over $50 \%$ of publications on biological SAS.

Dmitri Svergun was a panellist in the session entitled Community Data Standards of the workshop Working Towards Federating Structural Models and Data at the 2019 Biophysical Society Meeting (1 March 2019, Baltimore, USA). The workshop discussed in particular standards for representing, validating and archiving experimental data coming from the structural methods including SAS.

Andrew Allen continued to provide technical support to users of the NIST Standard Reference Material (SRM) SAXS Intensity Standard: NIST SRM 3600, and continues to encourage development of a SAXD $q$-Calibration Standard NIST SRM.

U-Ser Jeng continued to lead a team operating a SAXS beamline at the Taiwan Light Source of NSRRC, and has been leading the construction of a dedicated BioSAXS beamline at the $3 \mathrm{GeV}$ Taiwan Photon Source of NSRRC since 2016, which is expected to be operational in 2020 .

\section{U-Ser Jeng, Chair}

\subsection{Commission on Structural Chemistry}

The Commission on Structural Chemistry (CSC) encompasses a wide range of topics in the field of crystallography. There are extensive overlaps with other commissions including the Commission on Inorganic and Mineral Structures and the Commission on Crystallographic Teaching, as well as with important external bodies such as the Cambridge Crystallographic Data Centre (CCDC).

The Commission last met in person at the 2017 Hyderabad Congress and there agreed to focus on (i) support for appropriate crystallographic conferences and schools, in particular those that aim to expand crystallography to underrepresented regions such as South America and Africa; (ii) support for IUCr journals, through encouraging submission of excellent scientific results to IUCrJ and other journals; and (iii) building relations with other commissions and external bodies such as IUPAC and the CCDC. In considering the future composition of the Commission, it could also be of value to include a member or consultant to represent relevant industries.

In 2019, the CSC lent support to the following conferences and schools, which draw on crystallographers in the structuralchemistry sphere:

3rd LACA School on Small Molecule Crystallography, Mexico City, Mexico, March 2020.

4th International Symposium on Halogen Bonding (ISXB4), Stellenbosch, South Africa, March 2020.

6th European Crystallography School (ECS), Budapest, Hungary, July 2020.

AICS Italy Crystallography School, Parma, Italy, September 2020.

The CSC members interrogated the degree to which structural chemistry was represented as a science, rather than simply a tool, at each conference. Aspects such as support for students or early-career researchers were taken into account.
The diversity (gender, geographical distribution) of speakers was also identified as an important criterion for consideration of future applications for support. These factors played a role in the degree of support which was expressed to the Subcommittee on the Union Calendar.

Unfortunately, the COVID-19 pandemic meant that organizing committees had to make difficult decisions about whether to continue with planned events or not. Of the meetings detailed above, the LACA School had to be cancelled, while ISXB-4 was postponed to November 2020 (and has now been moved online) and the 6th ECS has been postponed by one year.

A further casualty of COVID-19 was the IUCr Congress 2020 in Prague, Czech Republic, which has also been postponed by one year. The CSC representatives on the International Programme Committee, Marijana Dakovic, Masaki Kawano and Catharine Esterhuysen, had compiled an extensive list of suggested microsymposia and keynote speakers, including some in collaboration with several other commissions. We look forward to a successful IUCr-25 in Prague in 2021, which will include a strong chemical crystallography programme.

\section{S. Bourne, Chair}

\subsection{Commission on Synchrotron and XFEL Radiation}

The mission of the Commission on Synchrotron and XFEL Radiation (CSXR) is to promote access to and awareness of the world's synchrotron radiation (SR) and X-ray freeelectron laser (XFEL) facilities to crystallographers worldwide. To this end, the Commission promotes the development of crystallographic instrumentation, technology and standards, and the synergies between storage-ring-based and linac-based next-generation XFEL sources. The bulk of the Commission's work is carried out via e-mail, with occasional face-to-face meetings held at selected conferences attended by a sufficient number of Commission members.

\section{Synchrotron-radiation and free-electron laser facilities}

Following the beginning of operations of the first '4th generation' storage ring, MAX IV in Sweden, many synchrotron facilities have been planning to upgrade or build new rings. For example, the ESRF is undertaking upgrade activities to be implemented in 2020. The APS upgrade was approved in December 2018, and replacement of the ring will start in 2022. Following in the footsteps of these two hard $\mathrm{X}$-ray facilities, Spring-8 is also planning significant upgrade programmes based on these new designs. In addition, SIRIUS, the fourth-generation Brazilian facility, was erected in 2018. The first loop of electrons of this 518-m circumference storage ring was achieved on 22 November 2019. Other facilities will also adapt the new high-brightness designs, including the $6 \mathrm{GeV}$ High Energy Photon Source (HEPS) to be built near Beijing, China, and the $3-\mathrm{GeV}$ facilities SLiT-J (Tohoku, Japan) and SPS-II (Thailand).

There are now five hard X-ray FELs open to users worldwide: the European XFEL in Germany, SACLA in Japan, PAL-XFEL in South Korea, SwissFEL in Switzerland and the 
LCLS in the USA. The first hard X-ray FEL based on accelerator technology, the European XFEL, started operation in late 2017, with all three self-amplified spontaneous emission (SASE) FELs at the European XFEL now operational. The EuXFEL linac operates with a repetition rate of $10 \mathrm{~Hz}$, designed to deliver up to 2700 pulses per pulse train with 4.5 MHz inter-pulse spacing, shared between three simultaneous experiments. After over a year of downtime for major construction to begin for LCLS-II (and LCLS-I upgrades), LCLS is starting user experiments in May 2020, with LCLS-II commissioning planned for summer 2020 and beam operation a year later. Also based on superconducting radio-frequency (RF) technology, LCLS-II is on track to deliver hard and soft XFEL pulses, with the latter at a repetition rate of up to $1 \mathrm{MHz}$. SHINE, a new superconducting RF-based XFEL in Shanghai, China, is planned to be commissioned in 2025, and will also offer up to $1 \mathrm{MHz}$ pulse repetition rates.

Commission membership

The current members (with year appointed) are: P. Grochulski (Canada) (2008), Chair; M. A. Garcia-Aranda (Spain) (2011); Y. Murakami (KEK, Japan) (2011); S. Pascarelli (France) (2011); J. Smith (USA) (2011); T. Tschentscher (Germany) (2014); E. Granado (Brazil) (2014); M. Kozak (Poland) (2017); S. Ramaswamy (India) (2017); and T. Hatsui (Japan) (2017). The consultants are R. Garrett (Australia) (previous Chair), D. Fritz (USA), S.-I. Adachi (Japan), M. Suchomel (USA), M. K. Sanyal (India), N. Zatsepin (Australia) and L. Keefe (USA).

Supported meetings, schools and workshops

The Commission provided letters of support and endorsement for the following meetings in 2019:

The Croatian Association of Crystallographers third edition of the workshop Hot Topics in Contemporary Crystallography (HTCC2019), 1-6 October 2019, Mlini, Dubrovnik, Croatia.

RapiData Course on Automated Data Collection. The Commission has endorsed this annual event for many years, and did so again for the school held at the Stanford Synchrotron Radiation Lightsource in May 2019.

In general, the Commission has strongly supported $\mathrm{IUCr}$ sponsorship for the purpose of assisting attendance by young researchers and scientists from developing countries.

Activities of members and consultants

The members of the Commission are active in key synchrotron and crystallography communities and conferences. For example:

Miguel A. G. Aranda is Chair of the ESRF Council for 2018-2020. He gave the following invited contributions related to our mission: (i) 'The role of raw powder diffraction data in peer review; past, present and future' at the Data Science Skills in Publishing: for Authors, Editors and Referees, a satellite workshop to the 32nd European Crystallographic Meeting, Vienna, August 2019; (ii) 'Quantification and analysis of amorphous components in cements by synchrotron ptychographic X-ray tomography' at the Workshop on Coherence at ESRF-EBS, Grenoble, September 2019; (iii) 'Diffraction for industries, businesses and health' at the Fifth
Meeting of the Italian (AIC) and Spanish Crystallographic (GE3C) Associations (MISCA V), Naples, September 2019; and (iv) two lectures at SESAME for the industrial workshop and the Hercules course organized by OPEN-SESAME project in Amman, October 2019.

Richard Garrett organized a one-day workshop, Advanced Light Sources in the Asia Oceania Region, held on 18 November 2019 as part of the 14th Asia-Pacific Physics Conference in Kuching, Malaysia.

Pawel Grochulski co-organized and lectured at the 9th Annual CLS Mx Data Collection School, Saskatoon, 25-29 June 2019; attended the SOLARIS Scientific Advisory Meeting 9-10 April 2019; gave a talk at the 14th International School and Symposium on Synchrotron Radiation in Natural Science (ISSRNS'2019), Zakopane, 9-14 June 2019; and gave a talk at the International Symposium on Diffraction Structural Biology, Osaka, 17-20 October 2019.

Eduardo Granado was a founding member and the first Chair of the Brazilian Synchrotron Users Group (LNLSUG) from November 2019; a member of the Scientific Committee of the 29th LNLS Annual Users Meeting (5-7 November 2019); and President of the Brazilian Crystallographic Association (ABCr), 2018-2020.

Sakura Pascarelli is Chair of the upcoming Gordon Conference on Research on High Pressure, Holderness, NH, USA, in July 2020; gave talks at the IUCr Current Trends and Future of Crystallography Workshop in Prague, Czech Republic, and at ICMRE Hefei, China, in May 2019; gave a lecture at the XV School on Synchrotron Radiation, Muggia, Italy, in September 2019; and was on the Scientific Organizing Committee of the LEAPS Meets Quantum Technology Conference, Elba, Italy, to be held in May 2020.

Maciej Kozak was Chair of the 14th International School and Symposium on Synchrotron Radiation in Natural Science (ISSRNS'2019), Zakopane, Poland, 9-14 June 2019, and Managing Guest Editor of Radiation Physics and Chemistry XAFS 2018 Special Issue. He gave talks at the 61st Polish Crystallographic Meeting, Wrocław, Poland, 27-28 June 2019; the Meeting of the Polish Physical Society, Kraków, Poland, 13-18 September 2019; the 11th International Conference on X-Ray Investigations of Polymer Structure (XIPS 2019), Ustron, Poland; and a lecture at the 5th Korean-Polish Conference on Protein Folding: Theoretical and Experimental Approaches, KIAS, Seoul, South Korea, 16-18 September 2019. He was Project Leader of the SOLCRYS beamline at the SOLARIS National Synchrotron Radiation Centre, Kraków, Poland, and a member of the XIPS 2019 International Advisory Board and of the Programme Advisory Committee for Condensed Matter Physics, Joint Institute for Nuclear Research, Dubna, Russia.

Nadia Zatsepin chaired the BioXFEL 6th Annual International Conference in February 2019; was an advisor for the Workshop on Macromolecular Serial Crystallography using the LCP Jet Injector at NSLS-II \& CFN Users' Meeting, New York, USA, in May 2019; and gave talks at the Transactions Symposium on Data Best Practices, American Crystallographic Association 2019 Annual Meeting, Covington, USA, 
in July 2019 and at the European XFEL Users' Meeting in February 2020.

\section{Asia-Oceania Forum for Synchrotron Radiation}

The Asia-Oceania Forum for Synchrotron Radiation Research (AOFSRR) is an international network of synchrotron and XFEL lightsource facilities and user organizations in the Asia-Oceania region. CSXR consultant Richard Garrett is Secretary-Treasurer of the forum, and CSXR member Youichi Murakami was AOFSRR President in 20152016. The major activities of the forum in 2019 were the third annual AOF Synchrotron Radiation School in early November, hosted by the National Synchrotron Radiation Research Center in Hsinchu, Taiwan, and the annual workshop, which ran in conjunction with the 14th Asia-Pacific Physics Conference in Kuching, Malaysia, also in November.

In its annual communique, issued at the Kuching workshop, the AOFSRR announced that it will hold the first AsiaOceania Synchrotron Radiation Instrumentation conference (AO-SRI) in 2020 in Sendai, Tohoku District, Japan, chaired by the Photon Science Innovation Center and hosted by Tohoku University International Center for SR Innovation Smart.

\section{Pawel Grochulski, Chair}

\subsection{Commission on XAFS}

The composition and roles of the Commission (CXAFS) in 2019 were as follows. Chair: Christopher T. Chantler (Australia); Secretaries: Valérie Briois (France) and Sofia Diaz Moreno (UK); liaison with the International Programme Committee: Giuliana Aquilanti (Italy); responsibility for the website: Sofia Diaz Moreno (UK); IXAS liaison: Krystyna Lawniczack-Jablonska (Poland); liaison with International Tables for Crystallography and IUCr Journals: Steven M. Heald (USA); IUCr dictionary of XAFS terminology: Narcizo M. Souza Neto (Brazil); coordinator for new editions of the Q2XAFS workshop: Krystyna Lawniczack-Jablonska (Poland); coordinator of funding support for IUCr Congress and Workshop: Dibyendu Bhattacharyya (India); working group on databases and coordinator of summary from Japan XAFS society: Yasushiro Inada (Japan). Consultants: Federico Boscherini (Italy), Pieter Glatzel (France), Richard Strange (UK) and Farideh Jalilehvand (Canada).

It is with great sadness that we announce the death of two of our colleagues belonging to the Commission: Carlo Lamberti (coordinator for IUCr Congress and workshop, and liaison to International Tables) and Hiroyuki Oyanagi (consultant).

IUCr Congress. The main activity of CXAFS in 2019 was preparation for the 25th IUCr Congress in Prague, Czech Republic. Following on from the first ideas discussed within the Commission in July 2018 during the XAFS2018 conference in Krakow, consultation among the Commission members was carried out in early 2019 in order to propose a short list of keynote speakers and microsymposia, which could be shared with other commissions to build the scientific programme of the Congress. Giuliana Aquilanti, who was responsible for the liaison with the International Programme Committee (IPC), defended this short list during the workshop Current Trends and Future of Crystallography in May 2019 in Prague. The following microsymposia were accepted.

Unshared microsymposium:

MS60 Catalysis: functionalized materials studied by XRD and XAFS. Co-Chairs: V. Briois (France), A. Roodt (South Africa).

Shared microsymposia:

MS61 XAS and crystallography allied for geomaterials and environmental problems (shared with the Commission on Inorganic and Mineral Structures). Co-Chairs: F. Mosselmans (France), A. Martucci (Italy).

MS57 Advanced methods for analysis of XAFS and crystallographic data (shared with the Committee on Data). CoChairs: M. Girogetti (Italy), M. Milanesio (Italy).

MS59 Disordered materials: spectroscopic and scattering techniques (shared with the Commission on Neutron Scattering). Co-Chairs: A. Trapananti (Italy), J. Simon (USA).

MS58 Spectroscopy applied to electrochemistry: operando studies (shared with the Commission on NMR Crystallography and Related Methods). Co-Chairs: D. Bhattacharyya (India), J. Plaisier (Italy).

MS37 Matter at extreme conditions at SR and XFEL: complementarity of spectroscopy and diffraction (shared with the Commission on High Pressure and the Commission on Synchrotron and XFEL Radiation). Co-Chairs: U. Zastrau (Germany), A. Rosa (France).

MS54 X-ray spectrometry and X-ray diffraction in art and archaeology (shared with the Commission on Crystallography in Art and Cultural Heritage). Co-Chairs: G. Cibin (UK), P. Bezdicka (Czech Republic).

MS138 The mineral/life interface - prebiotic chemistry, biomineralization, advanced biomimetic materials (shared with the Commission on Crystal Growth and Characterization of Materials). Co-Chairs: J. M. Garcia-Ruiz (Spain), G. Falini (Italy).

MS181 4th generation SR and XFEL facilities (shared with the Commission on Synchrotron and XFEL Radiation). CoChairs: M. Thunissen (Sweden), M. Yabashi (Japan), S. DiazMoreno (UK).

MS56 Combining X-ray diffraction and spectroscopy to characterize materials (shared with the Commission on Powder Diffraction).

Furthermore, two keynote speakers proposed by CXAFS were accepted: Federico Boscherini ('X-ray absorption spectroscopy and materials science: recent advances') and Britt Hedman ('The role of XAS in biology').

IUCr XAFS Workshop. The next workshop dedicated to XAFS for crystallographers will be held the day before the 25 th IUCr Congress. The workshop is sponsored by the IUCr. This one-day, almost free (a EUR 10 fee will partly cover a lunch pack and two coffee breaks) tutorial workshop will provide an overview of the physics and chemistry of X-ray absorption spectroscopy with a particular emphasis on its complementarity with diffraction techniques. The curriculum will include introductions to beamline instrumentation, measurement methods, and methods of data processing and 
analysis. Part of the workshop will be dedicated to hands-on basics EXAFS data analysis. The programme of this workshop is as follows.

(i) Introduction to XAS theory and basic experimental techniques for beginners - speaker Christopher Chantler;

(ii) Application of XAS in nano materials - speaker Anatoly Frenkel;

(iii) Application of XAS in catalysis - speaker Sofia DiazMoreno;

(iv) Application of XAS in energy materials - speaker Giuliana Aquilanti;

(v) MCR-ALS methods - speaker Elisa Borfecchia;

(vi) Pump-probe studies - speaker Xiaoyi Zhang;

(vii) Photon in-photon out spectroscopies - speaker Mathias Bauer; and

(viii) Hands-on training on basic EXAFS data analysis speakers Dibyendu Bhattacharyya, Diego Gianolio and Shu Hayama.

More details can be found at https://www.xray.cz/iucr/ workshops/xafs/. Registration can be done via the IUCr2020 registration system.

Article on CXAFS. At the request of the IUCr Executive Committee, C. T. Chantler, G. Aquilanti, S. Diaz-Moreno and V. Briois wrote an article reporting the roadmap for and 2018 activities of CXAFS, which was published in Materials Structure (2019), 26, 108. The purpose of this article was to introduce the Commission's activities together with the new science coming out of the field involving XAS and related spectroscopies based on photon in-photon out spectroscopy, with special emphasis on in situ and operando experiments in catalysis and energy-related materials, biomedical and life sciences, multivariate analysis and spatially resolved information with (scanning) transmission X-ray microscopy (STXM and TXM) at the nanometre scale, and microspectroscopy.

C. T. Chantler, Chair, and V. Briois and S. Diaz-Moreno, Secretaries

\section{Sub-committee on the Union Calendar}

The Sub-committee receives and considers requests for IUCr sponsorship and nominal financial support, and makes recommendations to the Executive Committee. Acting on the recommendations made by the Sub-committee, during 2019 the Executive Committee approved sponsorship of various schools and meetings, mostly with financial support. Those held in 2019 are listed at the beginning of this Report of the Executive Committee. Those scheduled for 2020, but approved in 2019, are listed below.

4th International Workshop on X-ray Crystallography in Structural Biology, The Islamia University of Bahawalpur, Pakistan, 25-27 February 2020.

Understanding Biology Through Structure, Santa Fe, New Mexico, USA, 16-20 March 2020.

4th International Symposium on Halogen Bonding (ISXB4), Stellenbosch, South Africa, 23-27 March 2020. 3rd LACA School on Small Molecule Crystallography, Universidad Nacional Autónoma de México, Mexico, 26-29 March 2020.

Powder Diffraction \& Rietveld Refinement School, Durham, UK, 29 March - 2 April 2020.

RapiData 2020, Menlo Park, California, USA, 30 March - 4 April 2020.

CCP4 Crystallographic School in South Africa: Data Collection to Structure Refinement and Beyond, Cape Town, South Africa, 31 March - 8 April 2020.

55 Erice School: Structural Drug Design 2020: Biology, Chemistry and Computers, Erice, Italy, 24-29 May 2020.

17th European Powder Diffraction Conference - EPDIC17, Šibenik, Croatia, 26-30 May 2020.

7th International School on Crystallization: Drugs, Foods, Agrochemicals, Minerals, New Materials (ISC2020), Granada, Spain, 29 May - 6 June 2020.

Workshop Renewable Energy and Sustainable Development 'Casamansun 2020' (7th Edition), Ziguinchor, Senegal, 4-6 June 2020.

European Crystallographic School (ECS6), Budapest, Hungary, 5-11 July 2020.

RIXS-REXS 2020: Workshop on Resonant Elastic and Inelastic X-ray Scattering 2020, Port Jefferson, USA, 15-17 July 2020.

School on SAXS/SANS and BioSAXS/BioSANS Data Analysis, Prague, Czech Republic, 19-21 August 2020.

Electron Crystallography School - 3D Electron Diffraction/ MicroED, Bridging Small Molecule and Macromolecular Crystallography, Tabor, South Bohemia, Czech Republic, 1922 August 2020.

Modern Trends in Computational Material Discovery 18th USPEX Workshop, Isfahan, Iran, 1-5 September 2020.

15th Biennial Conference on High-Resolution X-Ray Diffraction and Imaging (XTOP 2020), Minsk, Belarus, 13-18 September 2020.

10th International Conference of the Hellenic Crystallographic Association, Athens, Greece, 3-5 October 2020.

Crystallography for Space Sciences, Addis Ababa, Ethiopia, 1-5 November 2020.

Organizers of meetings wishing to seek IUCr sponsorship should submit applications at least nine months in advance of the meeting, writing to the Chair of the Sub-committee. For up-to-date contact information, application procedures and rules, see http://www.iucr.org/iucr/sponsorship/meetings.html.

Requests from satellite meetings may be submitted, and possible financial support requested, separately or through the Organizing Committee of the main meeting.

Meetings (other than satellite meetings) scheduled to be held within one month before or after an IUCr Congress will not be considered for sponsorship. For any meetings scheduled to be held between one and two months before or after a Congress, the application for sponsorship will be sent to the Chair of the Congress Programme Committee for approval, or otherwise. For meetings (other than satellite meetings) scheduled to be held, in the respective region, within one month before or after a meeting of a Regional Associate 
(American Crystallographic Association, Asian Crystallographic Association, European Crystallographic Association, Latin American Crystallographic Association), the applicants for sponsorship must seek approval of the Chair of the Regional Associate Organizing Committee.

IUCr sponsorship can only be given to meetings that are international in character and open to participants from all countries. For international meetings the membership of the Programme Committee is a good indication of this. National meetings are only supported if held in developing countries.

IUCr sponsorship should only be given to meetings that include a speaker policy and statistics relating to gender balance on the conference website. The policy should be consistent with the IUCr's policy on gender balance.

Active crystallographers should be involved in the organization of the conference and one or more sessions should deal with specific crystallographic topics. This does not automatically include any session on condensed matter physics, materials science or symmetry not related to crystallography. According to these criteria all meetings organized by $\mathrm{IUCr}$ Commissions automatically qualify.

Explicit support from the relevant IUCr Commission(s) is required for any international meeting (except for the meetings of Regional Associates) and from the Commission on Crystallographic Teaching for any international schools (except for those organized by an IUCr Commission).

The IUCr continues to support and uphold ISC's policy of non-discrimination and adheres to its decisions and procedures concerning the free circulation of scientists. Organizers of any meetings seeking IUCr sponsorship or support must assure the Sub-committee on the Union Calendar that the authorities of the country in which the meeting is to take place guarantee free entrance of bona fide scientists from all countries.

Travel support for young scientists is available for all meetings (including schools). This money should not be used for waiver of registration fees or for any purposes other than travel, accommodation and subsistence for the sponsored scientists. It is recommended that the presentations of young scientists supported by the IUCr should be in English.

Consideration should be given as to whether the proposed meeting is appropriate in subject, form and timing with respect to other related meetings.

Except in special cases, IUCr funds should not be used to sponsor more than one event per year in the same location.

Registration fees should be the same for both local and nonlocal participants.

Visiting Professorships. The IUCr Visiting Professorship Scheme aims to support some of the costs of having internationally recognized scientists as lecturers for short courses at workshops or schools organized in developing countries. These schools or workshops may have national or international character. Up to a maximum of three Visiting Professorships can be granted for a single event. Travel and insurance costs will be met by the IUCr, while the local organizers cover the accommodation/subsistence expenses. Visiting Professorships can be requested in conjunction with the application for IUCr funding of a meeting, or independently as a single action to obtain highly qualified international teaching support within a teaching programme of local character. Support from at least one IUCr Commission is required. Full details may be found at http://www.iucr.org/iucr/ sponsorship/vp.html.

\section{Committee for the Maintenance of the CIF Standard (COMCIFS)}

COMCIFS is responsible for maintaining and developing the suite of standards known as the Crystallographic Information Framework (CIF) on behalf of the IUCr. The committee consists of five voting members and a broad collection of advisers and observers. The current voting members are James Hester (Chair), John Bollinger (Co-Secretary), Brian McMahon (Co-Secretary), Herbert Bernstein and John Westbrook.

New dictionaries. No new dictionaries were approved this year.

Legacy dictionaries. No further legacy dictionaries were transferred to DDLm this year. The method for doing this has been finalized for the modulated-structure and electrondensity dictionaries.

International Tables for Crystallography Volume $G$. COMCIFS members are closely involved with the preparation of the second edition of International Tables Volume G (Definition and exchange of crystallographic data). Progress has been slow owing to clarification of the new foundational standards being a prerequisite to producing the volume. Further information is available in the report of the Commission on International Tables in Section 4.2.

Macromolecular standards. The wwPDB is responsible for a large and rapidly expanding collection of CIF definitions that encompass concepts and techniques used in the macromolecular community. In 2019 submission of entries in PDBx/ mmCIF format became mandatory as one of the final steps in moving away from the 1970s era PDB format. Much raw macromolecular diffraction data is in the form of imgCIFbased CBF files or NeXus NXmx application definition-based HDF5 files. In the culmination of an effort that began in 1995, a large portion of the macromolecular (MX) synchrotron and XFEL community agreed in 2019 on a new 'Gold Standard' for metadata to be provided in either imgCIF or NXmx diffraction images to permit processing of MX data at a wide range of facilities in a wide range of software packages. That agreement has been reported by Bernstein et al. [IUCrJ (2020), 7, 784-792].

Interactions with other groups. Herbert Bernstein represents COMCIFS on the NeXus International Advisory Committee (NIAC). This interaction was instrumental in reaching agreement on the 'Gold Standard' described above. COMCIFS is also closely involved with the IUCr Committee on Data (CommDat).

Events. This year's AIC International Crystallography School in Naples ('CIFiesta') had a strong focus on crystal- 
lographic information, and included several hours of lectures on the CIF system and dictionaries from CIF experts.

Looking forward. The 'Gold Standard' for macromolecular diffraction data will be submitted for approval to NIAC and COMCIFS in 2020, and will be incorporated into the next edition of Volume $\mathrm{G}$.

As flagged in previous years, an ever-shrinking group of people is drawn upon to support CIF maintenance and development. This situation is not sustainable, particularly as the first generation of CIF experts move into retirement. This situation did not improve in 2019.

James Hester, Chair

\section{Committee on Data (CommDat)}

For 2019 there are the following matters to report.

The IUCr Forum for Public Input to CommDat at https:// forums.iucr.org/ has had various new published reports and announcements posted there. These have been extensively accessed.

CommDat has participated fully in the work of the Prague IUCr Congress Programme Committee and the workshop immediately preceding it, see https://www.xray.cz/ $\mathrm{ms} /$ bul2019-2.htm and specifically CommDat's published contribution at http://www.xray.cz/ms/bul2019-2/commdat.pdf.

The top recommendation from the IUCr Diffraction Data Deposition Working Group (dddwg) final report (that raw diffraction data should be published with a doi cited in any future submitted article for publication) has led to the following initiatives. Firstly, Amy Sarjeant and Simon Coles, who are members of CommDat on behalf of the Commission on Structural Chemistry, announced a questionnaire in the IUCr Newsletter in December 2018 to survey views in the chemical crystallography community about the utility of preserving its diffraction images. The deadline for answers to the questionnaire was March 2019. Secondly, this top recommendation was taken forward by the IUCr Commission on Biological Macromolecules (CBM) as a proposal to the IUCr Executive Committee, following the support of those present at its Open Commission Meeting at the IUCr Congress in Hyderabad in 2017. As discussed in Hyderabad, CommDat had endorsed this CBM proposal. CommDat worked with the $\mathrm{CBM}$ in the publishing of FAIR (findable, accessible, interoperable and reusable) diffraction data policy details for macromolecular crystallography papers in Acta Crystallographica Sections D and F, IUCrJ and J. Appl. Cryst. [see e.g. Acta Cryst. (2019). D75, 455-457, https://doi.org/10.1107/ S2059798319004844].

CommDat is seeking to ensure that raw diffraction data across all the IUCr's Commissions should be 'FAIR'. A version of checkCIF for raw data to automate the reusability of raw diffraction data is under development. Collaboration with COMCIFS is progressing towards this goal.

A CommDat workshop was held at the ECM in Vienna in August 2019 on Data Science Skills in Publishing: for Authors,
Editors and Referees, https://ecm2019.org/satellites/datascience-skills-in-publishing/.

CommDat actively supported the CIF Fiesta Training event in August/September 2019 led by the Italian Crystallographic Association, http://www.cristallografia.org/aicschool2019.

CommDat lecturers contributed to sessions primarily dedicated to crystallographic data at the ACA in Covington, Kentucky, USA in July 2019 (see https://tinyurl.com/y3rzg5xb) as well as the very general open data symposium organized by PaNOSC (Photon and Neutron Open Science Cloud) in Trieste in November 2019 (see https://tinyurl.com/y4lvq47j).

John R. Helliwell, Chair

\section{IUCr Newsletter}

Over the last year, four issues of the online Newsletter have appeared with an average of 32 items in each issue, and continue to be well received. A modest amount of full-page and banner advertising was achieved but it is hoped this can be increased to help cover costs.

During this time several interesting and important articles were published. For example, our audience was particularly engaged by a fun article on Crystallography in the Movies, which resulted in several letters to the Editor.

We also published articles with educational content, for example, a guide to using the terms crystal structure and lattice correctly. The confusion between these crystallographic terms is widespread, especially within the chemistry and physics communities. This article has been useful in drawing attention to their usage to those outside of the crystallography community via vigorous arguments on Twitter. Another article was written by the Editor on Bragg's balls and the demonstration of crystal packing.

Other IUCr activities were covered, such as the formation of a Gender Equity and Diversity Committee, and a call was put out for new contributing authors for the IUCr Online Dictionary of Crystallography. In addition, readers were brought up to date with the IUCr's outreach activities, such as the Crystallography in Africa initiative and results from the crystal-growing competition. The People and History section celebrated recent awards and the lives of crystallographers no longer with us. Our Crystallography in Africa programme was illustrated by an inspiring article about a young African scientist and his journey into crystallography (https://www. iucr.org/news/newsletter/volume-27/number-4/the-journey-ofa-young-african-scientist-to-crystallography).

A special section was introduced to provide information about the forthcoming IUCr Congress. In addition, the Newsletter remains an excellent vehicle for providing extra publicity for IUCr Journals content and news of special issues, new Editors $e t c$. It is also an attractive repository for meeting reports. Each issue was sent electronically to more than 13500 crystallographers and structural scientists worldwide.

There has been a change in the list of Regional Editors. We thank Amy Sarjeant for representing the USA and Canada, and welcome two new Editors to replace her: Tiffany Kinni- 
brugh and Andrey Yakovenko, both at Argonne National Laboratory, IL, USA.

Finally, the Newsletter would not have been possible without the active help of a number of members of the Chester staff, including Andrea Sharpe, Michele Zema, Peter Strickland and Brian McMahon. Special thanks are due to the Technical Editors, Mark Bates, Sarah Froggatt and Jennifer Skade.

Mike Glazer, Editor

\section{IUCr/Oxford University Press (OUP) Book Series Committee}

The Book Series Committee members individually provided assessments of two monograph book proposals, one being a second edition, which I then brought together as Chair's reports. These two reports were first provided to the IUCr Executive Committee, which endorsed them, and then they were submitted to Oxford University Press (OUP). A third book, in full draft form, was requested by OUP to be commented on by the Book Series Committee although outside the monographs or teaching books. This report was first provided to the IUCr Executive Committee, which endorsed it, and then it was submitted to OUP. Likewise a second, i.e. duly revised, full draft was received, a report was again provided to the IUCr Executive Committee, which endorsed it, and then it was submitted to OUP. In order to ensure consistency to IUCr nomenclature policies, and to reduce the chance of errors, we have reaffirmed to OUP the need for us to assign volunteer(s) with requisite subject expertise, ideally from our Committee, so as to review a full draft of a new text in our Book Series before publication by OUP in the IUCr's name.

John R. Helliwell, Chair

\section{Gender Equity and Diversity Committee (GEDC)}

There was an overwhelming response to the IUCr's call for expressions of interest to join this Committee. Owing to the overwhelming response, the IUCr approved an expansion from 10 to 12 members ( 7 women, 5 men). The Committee includes five from Europe, four from Asia and three from the Americas: Jenny Martin, Chair (IUCr Executive Committee member, Australia); Sven Lidin (IUCr President, Sweden); Natalie Alvarez (Uruguay); Ruchi Anand (India); Christine Beavers (UK); Annalisa Guerri (Sub-committee on the Union Calendar, which awards funding for crystallography conferences, Italy); Genji Kurisu (Japan); Helen Maynard-Casely (Australia); Claire Murray (UK); Bernie Santarsiero (USA); Eddie Snell (USA); and Michele Zema (IUCr Executive Outreach Officer). A number of other people have expressed their interest in helping in other ways (e.g. on subcommittees etc.).

The Committee drafted an IUCr code of conduct and an IUCr Gender Equity and Diversity Statement. These were submitted to the IUCr Executive Committee at their meeting in Covington and adopted with minor changes.

An IUCr web page for the GEDC was established (https:// www.iucr.org/iucr/governance/advisory-committees/gedc). The web page hosts the GEDC diversity statement and code of conduct.

The GEDC also recommended that the IUCr:

Develop an updated mission, vision, values, statement that reflects diversity and inclusivity and the UN sustainable development goals, so that these can inform all policies.

Develop a rights and responsibilities document (see https:// sciencepolicy.agu.org/files/2013/07/AGU-Responsibilities-andRights-of-Scientists-Position-Statement-Adopted-2017-1.pdf).

Sign up to the Hague ethical guidelines: https://www.opcw. org/hague-ethical-guidelines.

Curate a list of crystallographers willing to be gender equity and diversity advisors for conference committees.

Jenny Martin, Chair

\section{The IUCr Crystallography in Africa Initiative}

During 2019 three important events were organized within the framework of the IUCr's Africa Initiative project.

(1) The second Pan African Conference on Crystallography (PCCr2) took place in Accra, Ghana, in January 2019. Almost 40 full bursaries for travel, registration and accommodation were given to African $\mathrm{PhDs}$, postdocs and young professors from a budget of EUR 20000 . The main donors were UNESCO, ICSU, LAAAMP, the IUCr, the ECA and Seme City.

(2) A meeting of the steering committee of the African Crystallographic Association (AfCA) was held. The AfCA steering committee has representatives from several African regions [North Africa: Dr Rim Benali Cherif (Algeria); Western Africa: Dr Marielle Agbahoungbata (Benin); Central Africa: Dr Adam Bouraima (Gabon) and Dr Albert Lumemba (DRC); South Africa: Dr Gift Mehlana (South Africa); Eastern Africa: Dr Seham Kamal (Egypt)], a Secretary (Dr Patrice Kenfack, Cameroon) and a Chair (Professor Delia Haynes, South Africa). The steering committee respects gender balance and all members are young professors or postdocs. To assist the steering committee in their reflections, several ex officio members were proposed: Professor Alessia Bacchi (former ECA President), Dr Michele Zema (IUCr Executive Outreach Officer) and Professor Claude Lecomte. The ex officio members do not vote and it is hoped that they will be consulted less frequently as time goes on. The steering committee has already proposed rules for and considered bids for the next PCCr3 and 4 meetings, and is working on the statutes and by-laws of AfCA. An almost exhaustive list of African crystallographers, equipment and research areas is being established by the regional delegates. The next task of the AfCA steering committee will be to launch AfCA, which will be done during PCCr3. Relations between AfCA, the ECA and the African Light Source (AfLS) will also be discussed during PCCr3. 
(3) An OpenLab was held in Seme City, Benin, 12-25 May 2019. This was a very important project for the promotion of crystallography in Africa. A general and fundamental crystallography course was taught together with hands-on experience using a D8 single-crystal diffractometer lent for free by Bruker. The funding for the school was mostly provided by the government of Benin through the administration of Seme City. The IUCr's Africa Initiative provided bursaries together with UNESCO. During this OpenLab the crystal structure of a molecule which was synthesized and crystallized in Benin at the University of Cotonou was solved, and an article describing this work was later accepted for publication in Acta Crystallographica Section E. An $I U C r$ Newsletter report about the school was also written.

The Africa Initiative project also continued to help to equip African laboratories. A second-hand single-crystal diffractometer was donated by Bruker France to the University of Dschang, the shipping and installation of which was financially supported by the IUCr and the University. It will be inaugurated at the OpenLab in Dschang in 2020. Bruker also donated a new X-ray generator for the powder diffractometer they sent to the University of Dschang in 2016 under the Africa Initiative project. The UNESCO office at Yaoundé assisted in this collaboration. Dr Bolivar Voufack has been appointed by the physics department to be in charge of diffraction measurements related to physics.

Bruker now propose to offer each year a new up-to-date single-crystal diffractometer at cost. This offer will be used to install a D8 Quest ECO equipped with a photon-II detector and a low-temperature device at the Seme City X-ray Laboratory in Porto Nuevo, Benin, in May 2020 when the building will be ready. The total cost has been paid by the government of Benin after Dr Zema and I helped to negotiate the deal between Bruker and Seme City.

Claude Lecomte, Chair of Steering Committee

\section{Regional Associates}

\subsection{American Crystallographic Association (ACA)}

The American Crystallographic Association, Inc. (ACA) is a nonprofit, scientific organization with more than 1000 registered members. The ACA was founded in 1949, and its objective is to promote interactions among scientists who study the structure of matter at atomic (or near atomic) resolution. For more details, please visit the regularly updated, very informative and easy to navigate ACA website, http:// www.amercrystalassn.org.

The 2019 ACA Council consisted of Joseph Ferrara (President), Brian Toby (Vice-President), Lisa Keefe (Past President), Ilia Guzei (Treasurer), Diana Tomchick (Secretary) and George Lountos as the Young Scientists Special Interest Group (YSSIG) representative to the Council (ex officio). Tomislav Friscic served as the Canadian National Committee for Crystallography (CNCC) representative and
Hanna Dabkowska as the IUCr representative (ex officio). Bill Duax was the Chief Executive Officer (CEO) and S. N. Rao the Chief Financial Officer (CFO), Kristin Stevens the Director of Administrative Services and Kristina Vitale the Membership Secretary. In 2019 the Council only met three times, as the number of in-person meetings was reduced. Once-a-month teleconferences have been introduced and proved to be successful.

Bill Duax retired at the end of 2019 as CEO, but we all hope that he will be around for many years helping us all with his experienced advice. Lisa Keefe volunteered to act as CEO for 2020 while the Council figures out how to restructure the CEO role.

The 2019 (69th) Annual Meeting was held 20-24 July in Covington, Kentucky. Stephan Ginell and Vivien Yee cochaired this meeting. Poster Chairs were Louise Dawe and David Rose. During the keynote presentation 'Michael G. Rossmann (1930-2019), Pioneer in Crystallography of Macromolecules \& Viruses', Michael was remembered by colleagues and friends. There were 519 attendees at the ACA meeting and some financial profit was achieved. Meeting statistics are available at https://www.amercrystalassn.org/ past-meetings.

The 2019 ACA Award Winners are Brian Toby and Robert Von Dreele (Trueblood Award), Eaton (Ed) Lattman (Fankuchen Award), Bryan Chakoumakos (Bau Award) and Efrain Rodriguez (M. C. Etter Early Career Award). The Covington meeting was supported by some 25 sponsors (including an IUCr travel award for young scientists). 2019 ACA Fellow titles were bestowed on Craig M. Brown, Susan K. Byram, Charles W. Carter Jr, Elspeth F. Garman and Xiaoping Wang.

Details about the ACA activities, reports and projects can be found in the excellent publication ACA RefleXions, https:// www.amercrystalassn.org/aca-reflections (Editors Paul Swepston and Edwin D. Stevens). The results of ACA 2019 election are also published there.

The 2020 (70th) Annual ACA Meeting will have the overall theme of 'Training the Next Generation' and it will be held in San Diego, California, 2-6 August 2020, the Keynote Speaker will be a Nobel Prize laureate, Venki Ramakrishnan. The Programme Chairs are Nozomi Ando and Carla Slebodnic and the Poster Chairs are Louise Dawe and Tiffany Kinnibrugh.

The 2021 (71st) ACA Meeting will be held in Baltimore, MD, 31 July - 3 August, and the 2022 (72nd) in Portland, OR, 30 July -2 August.

The ACA Council works very efficiently to achieve a balanced budget. The main income comes from the annual meetings and from the membership dues. The Council Members volunteered above 900 working hours in 2019.

Other updates: Structural Dynamics, an ACA/AIP journal, achieved an impact factor of 2.99 in 2019, https://www. researchgate.net/journal/2329-7778_Structural_Dynamics. Majed Chergui recently stepped down as the Editor-in-chief of this journal.

The National Science Foundation (NSF) recently de-funded the US National Committee on Crystallography (USNC/Cr). 
It remains to be decided which organization will be the USA's Adhering Body to the IUCr after 2020.

The ACA supported many progressive statements and actions regarding the situation of science and social activities in USA (often acting together with the APS).

The very interesting project of creating a Certified Crystallographer programme is under discussion.

The 2019 ACA Summer Course was held 23-30 June on the campus of the Northwestern University. The 2020 ACA Summer Course in Chemical Crystallography, info@ acasummercourse.net, will be held at Purdue University, 31 May - 6 June.

The Canadian National Committee for Crystallography (CNCC), http://xtallography.ca/, is chaired by Tomislav Friscic, Vice-Chair is Louise Dawe, the Secretary is Michel Fodje and the Treasurer is Brian Patrick. In May 2019 they organized the excellent 10th Canadian Chemical Crystallography Workshop (CCCW19) in Montreal. In 2020 the 11th Canadian Chemical Crystallography Workshop (CCCW20) will be held in Winnipeg, 19-22 May.

The 13th Canadian Powder Diffraction Workshop (CPDW 13) will be hosted by the Canadian Light Source in Saskatoon 19-22nd May.

The 2nd Canadian Materials Diffraction Workshop (CMDW2020) will be held 16-19 June 2020 at the University of Alberta, Edmonton.

\section{H. A. Dabkowska, IUCr Representative}

\subsection{Asian Crystallographic Association (AsCA)}

AsCA continues to play a leading role in the nurturing of collective crystallographic activities in the Asia-Pacific region with successful scientific meetings being held in those years in which there is no IUCr Congress and General Assembly. The most recent AsCA meeting was held in Singapore in December 2019.

AsCA Executive officers. In 2019 the office bearers of AsCA (elected in Hanoi in December 2016) were Jennifer Martin (President, Australia), Xiao-Dong Su (Vice-President, China), Edward R. T. Tiekink (Secretary/Treasurer, Malaysia) and Pinak Chakrabarti (Immediate Past President, India). New office bearers for 2020-2023 were elected at the AsCA Council meeting in Singapore in December 2019. These are XiaoDong Su (President, China), Genji Kurisu (Vice-President, Japan), Siegbert Schmid (Secretary/Treasurer, Australia) and Jennifer Martin (Immediate Past President, Australia).

AsCA scientific meeting in 2019. The 16th AsCA scientific meeting was held in Singapore in December 2019, with Professor J. J. Vittal as the Local Chair (https://asca2019.org/). The conference attracted 526 participants from 29 countries. Japan (93), India (68), Korea (64), Singapore (55), China (46) and Taiwan (35) were represented by the largest number of participants. The conference adopted the IUCr's gender equity statement and aimed for gender balance where possible. The International Programme Committee comprised 11 female and 10 male members including Co-Chairs Jenny Martin, Sara Sandin and Edward Tiekink. The Local Orga- nizing Committee comprised 1 female and 8 male members (11\% women). During the conference 22/66 (33\%) symposia Chairs, 68/172 (39\%) oral presenters and 19/46 (41\%) younger participants were female. Overall 161 attendees were women (31\%).

The AsCA conference goal is to strive for gender balance in plenary/keynote speakers, invited and selected microsymposia speakers and Co-Chairs. We know this will take time, so we are collecting and reporting data to provide a baseline with the aim to move towards gender balance at each successive conference (i.e. no less than $40 \%$ delegates/speakers of one gender). Gender data for the past two AsCA conferences are as follows. Women: average 31\%, 16th AsCA meeting (Singapore, 2019) 31\%, 15th AsCA meeting (Auckland, 2018) $31 \%$ (note: 51 of 477 undisclosed). Plenary/keynote and other special invited speakers: average 50\%, 2019 40\%, $201860 \%$. Invited and selected microsymposia speakers (including all oral presenters): average 34\%, 2019 37\%, 2018 31\%. CoChairs: average 40\%, 2019 33\%, 2018 46\%. Programme Committee: average 48\%, 2019 52\%, 2018 43\%. Local Organizing Committee: average 21\%, 2019 11\%, 2018 30\%.

The financial report for the conference was not available at the time of writing this report.

Future AsCA meetings. In 2018, Malaysia was selected to host the 17th AsCA Conference at Sunway University, Petaling Jaya, Malaysia, in December 2021. An expanded local organization committee is being established, a professional conference organizer has been appointed and dates and venue are close to being finalized. Note: The recent COVID-19initiated postponement of the 2020 IUCr Congress and General Assembly to 2021 means that the 17th AsCA conference dates will need to be confirmed during the current year.

Bids for AsCA2022 were received from Korea, Republic of (Jeju Island) and China, Taiwan (Taipei). Presentations in support of these were made in a special session during the AsCA conference in Singapore. A vote was held to select the successful bid. Korea, Republic of was selected by ballot to host AsCA2022.

The AsCA website (https://asca.iucr.org/) is currently being updated (thanks to Edward Tiekink).

Siegbert Schmid, Secretary/Treasurer

\subsection{European Crystallographic Association (ECA)}

The ECA is a scientific association among national members and individual members and corporate affiliates. It has 13 SIGs (Special Interest Groups) and 3 GIGs (General Interest Groups). The ECA's main event - the ECM (European Crystallographic Meeting) - was held in Vienna, Austria, 18-23 August with 15 satellite meetings and workshops preceding the conference. In total, 404 people were registered for these meetings. There were three conference chairs: Klaudia Hradil, Kristina Djinovic Carugo and Ronald Miletich.

At ECM32 there were 17 plenary and keynote lectures and 48 microsymposia. Participants: 193 ECA individual members, 
468 other regular participants, 247 students or retired people, 76 exhibitors, 36 accompanying persons, 40 children. The highest number were from UK. Overall, 1061 people. The percentage of females was nearly $35 \%$. This was also reflected in posters, Co-Chairs, invited talks and even higher in selected talks.

The numbers of abstracts in different focus areas were 165 (179 at ECM31) in biological and macromolecular crystallography, 103 (158) in materials and minerals, 117 (119) in physics and fundamental crystallography, 142 (157) in chemical crystallography, 64 (116) in experimental and computational techniques and 17 (59) in general interest sessions.

As usual, two sessions of the ECA Council Meeting also took place at the ECM.

The main ECA prize - the Max Perutz Prize - was awarded to Professor Elspeth Garman from the Department of Biochemistry, University of Oxford, UK, in recognition of her invaluable contribution to the field of macromolecular crystallographic methods by developing tools and methods for improving the quality of diffraction data. The Erwin Felix Lewy Bertaut Prize for young scientists was not awarded in 2019. A new prize was introduced: the International Kálmán Prize preserves the memory of the late Alajos Kálmán, an eminent scientist in the field of chemical crystallography. This prize was established by the Hungarian Chemical Society and was endorsed by the ECA. The first prize was awarded to Professor Luigi Nassimbeni from the University of Cape Town, South Africa.

ECM33 will be in Versailles, France, and will be organized together with synchrotron Soleil. It was originally planned for 2021, but after the IUCr Congress in Prague was moved from 2020 to 2021, ECM33 was also moved to 23-27 August 2022 (the 2021 organizers were Sylvain Ravy, Jean-Paul Itié and Andrew Thomson) and ECM34 to August 2024 in Padova, Italy.

The ECA school - the European School of Crystallography (ECS) - that is organized under detailed ECA guidelines was planned for beginning of July 2020 in Budapest, and like many meetings, it was moved to the same time in 2021.

An African Crystallography Steering Committee has been established and six African regions defined. It is expected that the African Crystallographic Association (AfCA) will be founded at the third African crystallographic conference, the PCCr, in February 2021 in Kenya. From then on, African countries will no longer be members of the ECA.

There is a new candidate for national membership Romania. There are still problems with re-establishing contacts with Russia.

Schools and workshops were supported in 2019 by more than EUR 10000 (11 applications).

The ECA Council decided to terminate the ECA's membership in ISE (Initiative for Science in Europe, https:// initiative-se.eu/) because the organization was not very active. However, this has changed after the appointment of a new Secretary. Currently, the ECA is on (non-paying) observer status at ISE. ISE has launched a petition for More Invest- ment in Horizon Europe. The ECA has signed and supported this petition.

The Executive Committee regular Winter Meeting was held in February 2019 in Berlin, at the office of current ECA President, Udo Heinemann.

Discussion continues about how to strengthen the position of the ECA as European association; there are some legal issues and the possibility of professional management. The ECA is registered in the Netherlands and it seems now that the best option would be to have charity status. The charity status will require a moderate number of changes to the ECA statutes (declaration of objectives, rules for dissolution and settlement) that are now in preparation and will be submitted to the ECA Council.

\section{R. Kužel, IUCr Representative}

\subsection{Latin American Crystallographic Association (LACA)}

The Latin American Crystallographic Association (LACA) had two main events in 2019. The II LACA School took place 1-6 October and the IV LACA Meeting 7-10 October at Universidad Industrial de Santander (UIS), Bucaramanga, Colombia. Professor José Antonio Henao (UIS) was the Chair of the organizing committee.

The program of the II LACA School included lectures and demonstrations on single-crystal and powder diffraction techniques and was taught by 11 international and 3 Colombian instructors. Seventy-five young researchers and students from Bolivia, Brazil, Chile, Colombia, Costa Rica, Ecuador, Mexico, Peru and Venezuela attended the school; 28 of them were awarded scholarships through IUCr funding and 17 received scholarships from the International Centre for Diffraction Data (ICDD). The female-to-male ratio for the participants was 47:53. In addition to financial support, the IUCr provided online access to International Tables for Crystallography during the school. The Cambridge Crystallographic Data Centre (CCDC) provided licences for 30 days to the Cambridge Structural Database and the ICDD to the PDF-4 databases.

The IV LACA meeting included plenary lectures delivered by IUCr President Sven Lidin (Sweden), Abel Moreno (Mexico), Professor Silvia Cuffini (Brazil) and Professor Iris Torriani (Brazil), who received special recognition for her long-standing scientific career and for her work in favour of the Latin American crystallographic community. Attendees were from Argentina, Bolivia, Brazil, Chile, Colombia, Costa Rica, Ecuador, Germany, Italy, Mexico, Peru, Sweden, Uruguay, the USA and Venezuela with a 40:60 female:male ratio. The meeting included 12 semi-plenaries, oral presentations, posters and a commercial exhibit. From the two poster sessions, eight posters presented by students were selected for prizes awarded by LACA, IUCr Journals, ICDD's Powder Diffraction Journal, the CCDC, Journal of Chemical Crystallography, CrystEngComm and Crystal Growth \& Design.

The Colombian Crystallography Society met for the first time during the meeting. At the assembly, the need to strengthen collaboration between laboratories and to activate 
the adherence of Colombia to the IUCr were discussed and approved. A committee composed of representatives from Universidad Industrial de Santander, Universidad Nacional de Colombia, Universidad del Valle, Universidad de Los Andes and the Colombian Geological Service was set up to take the necessary steps to request membership of Colombia to the IUCr during the next General Assembly in Prague in 2020.

At the LACA Assembly, the report on the activities carried out in 2018-2019 was presented by LACA President José Reyes-Gasga (Mexico), as well as a report from Professor Iris Torriani. Abel Moreno presented a proposal to host the 2026 IUCr Congress and General Assembly in Mexico and the LACA Assembly approved support for a bid from the Mexican Crystallography Society (SMCr) to host this event. The SMCr will present a bid at the next General Assembly in Prague. The LACA Assembly discussed the planning of the 2021 and 2022 meetings, with Costa Rica and Uruguay as possible sites for the V and VI LACA meetings.

Graciela C. Diaz de Delgado, IUCr Representative

\section{Representatives on Other Bodies and Scientific Associates}

13.1. ICTNS (the Interdivisional Committee on Terminology, Nomenclature and Symbols, a committee of IUPAC)

The Chair of the Commission on Crystallographic Nomenclature is a member of the ICTNS.

Requests to referee papers and reports submitted to IUPAC arrive regularly. Most submissions are in specialized areas unrelated to crystallography, but a review was written for a surprisingly interesting manuscript discussing end-of-line hyphenation.

In January 2017 an IUPAC project titled Backup, Maintenance, and Redevelopment of the IUPAC Gold Book Website started (see https://iupac.org/projects/project-details/ ?project_nr=2016-046-1-024). The first e-mail to the ICTNS about this project was sent in January 2018; there were no further communications until 2019. During the last year the ICTNS has been circulating documents and meeting electronically to set up procedures for adding new definitions to the Gold Book. Considerable time is being contributed to this effort by some of the other ICTNS members but progress has been slow.

Carolyn P. Brock, IUCr Representative

\subsection{International Science Council (ISC)}

The International Science Council (ISC) is a non-governmental organization with a global membership that brings together 40 international scientific unions and associations (including the IUCr, IUPAC and IUPAP) and over 140 national and regional scientific organizations including academies and research councils. The ISC was created in 2018 as the result of a merger between the International Council for Science (ICSU) and the International Social Science Council
(ISSC) to bring together the natural and social sciences and is the largest global science organization of its type.

The goal of the ISC is to emphasize the importance of scientific understanding to society and act as the global voice of science. As part of that mission, the ISC will strive to:

(i) speak for the value of all science and the need for evidence, informed understanding and decision-making;

(ii) stimulate and support international scientific research and scholarship on major issues of global concern;

(iii) articulate scientific knowledge on such issues in the public domain;

(iv) promote the continued and equal advancement of scientific rigour, creativity and relevance in all parts of the world; and

(v) defend the free and responsible practice of science.

The activities of the ISC are numerous; listed below are four of particular relevance to members of the IUCr.

(1) Funding science for sustainability. The International Science Council and its partners convened a global forum held in Washington DC in July 2019, to mobilize global sustainable science action to realize the 17 ambitious Sustainable Development Goals (SDGs) of the UN's 2030 Agenda. Through the Decade of Global Sustainability Science Action, science funders and the research community seek to:

(i) apply a holistic and systems approach to tackling pressing global challenges, treating the SDGs as an indivisible agenda;

(ii) support transformative, high-impact and transdisciplinary knowledge creation;

(iii) promote mission-driven research, but also harness the contributions of fundamental research; and

(iv) support enabling activities, e.g. capacity development and knowledge brokerage.

The mission of the ISC is based on the belief that science has a fundamental role to play in achieving progress towards the implementation of the SDGs by providing evidence for decision-making and informing the development of more sustainable solutions. No single country will be able to meet all of the goals by the 2030 deadline. Only an urgent, more ambitious and well resourced global plan of action will ensure that the goals are met. Science can accelerate transformative change by identifying the most significant interactions within the SDGs, help to fill in data gaps and monitor progress. The next meeting of this group was to take place in May 2020 in conjunction with the Global Research Council's annual meeting, 24-25 May 2020. However, owing to the COVID-19 pandemic, the meeting was postponed until the first trimester of 2021.

(2) Endorse or co-sponsor International Years. The ISC endorses or co-sponsors and participates actively in many international scientific events, including International Years or Decades of Science initiated and implemented by ISC members and/or partners, for example the International Year of Basic Sciences for Development: 2020 (organized under the leadership of the International Union of Pure and Applied Physics) and the International Year of Plant Health: \#IYPH2020, which aims to inspire people to learn more about 
plant health, which we all depend on, and to take concrete action.

(3) Grants Programme. The Grants Programme was created by ICSU prior to the merger. Proposals needed to be led jointly by at least two Scientific Unions, were competitive and peer-reviewed, and needed to focus on innovative, international and multidisciplinary work, have a focus on science education, outreach and public engagement activities, and to mobilize resources for international scientific collaboration. The IUCr joined with IUPAP for one of three funded proposals: IUPAP-IUCr: Utilisation of Light Source and Crystallographic Sciences to Facilitate the Enhancement of Knowledge and Improve the Economic and Social Conditions in Targeted Regions of the World. This project was called LAAMP (Lightsources for Africa, the Americas and the Middle East Project) but has since been expanded to include SE Asia and is now LAAAMP (Lightsources for Africa, the Americas, Asia and the Middle East Project). With this project, the IUCr partners with IUPAP and ISC to enhance advanced light sources and crystallographic sciences in Africa, the Middle East, SE Asia, Mexico and the Caribbean.

(4) Science news/blogs. The ISC website (https://council. science/current/) features stories on a number of current topics. In July 2020, the site promoted the IUCr website highlighting a number of key discoveries related to how crystallography has contributed substantially to our understanding of the coronavirus and contributing to COVID-19 research and vaccine development: https://council.science/ current/news/crystallographers-unite-to-tackle-coronavirus/.

M. Hackert, IUCr Representative

13.3. International Science Council Committee on Data for Science and Technology (CODATA)

CODATA is the interdisciplinary Committee on Data for Science and Technology of the International Science Council. Full details of CODATA's activities are available from its website at http://www.codata.org.

In September 2019, CODATA organized a meeting in Beijing entitled Towards Next-Generation Data-Driven Science: Policies, Practices and Platforms (https://codata.org/ events/conferences/codata-2019-beijing/). This included a session entitled The Key Role of the Scientific Unions in Enabling Transdisciplinary Data-Intensive Science in Support of Global Challenges. This was within the Data Integration initiative of CODATA (http://dataintegration.codata.org/). James Hester (COMCIFS Chair) attended as the representative of the IUCr. The IUCr has been an active participant in this initiative of CODATA to explore data integration between the data standards of various Unions. This effort, described in detail at https://zenodo.org/record/1319525\#. $\mathrm{X} 19$ sGiPgq00, commenced in Paris with an inter-unions workshop in June 2017, with a further workshop in London in November 2017. Both workshops were well received. John Helliwell represented the IUCr in June 2017 and Simon Coles in November 2017. At the Beijing session in 2019 the other
Unions taking part were the International Union on Geodesy and Geophysics (IUGG), the International Union of Geological Sciences (IUGS), and the International Astronomical Union (IAU), from the outside perspective of the International Virtual Observatory Alliance (IVOA). We note that 'data integration' can be shown to work in specific cases such as the Ocean Data Interoperability Platform, http://www. odip.org/, which featured well in the Paris Workshop in 2017, and is clearly desirable in that example. However, the Beijing 2019 session revealed that between the more-diverse International Unions little progress was documented. We commend that a more specific focus on interoperability, included within the initiative, be adopted for a more obviously effective progress in this domain by CODATA. Indeed, data interoperability was effectively explored at the International Data Week in Botswana in November 2018 in a double session jointly organized by IUPAC and the IUCr entitled Data interoperability in chemistry, biology, and crystallography: Enabling multidisciplinary solutions to societal challenges.

We are very grateful to Dr Simon Hodson, Executive Director of CODATA, who gave the opening lecture at the CIFiesta Naples School in August/September 2019, an information-, metadata- and data-centric school organized by the Italian Crystallographic Association with participation from members of COMCIFS and CommDat.

John R. Helliwell, IUCr Representative

\subsection{ISC Committee on Space Research (COSPAR)}

COSPAR's main objective is to promote international collaboration in scientific research in Space, with an emphasis on the exchange of results, information and opinions (http:// cosparhq.cnes.fr/). This organization is responsible for developing world standards for the Space environment and its protection.

COSPAR's highest body is the Council. The Council comprises the Committee's President, Representatives of Member National Scientific Institutions and International Scientific Unions, the Chairs of COSPAR Scientific Commissions, and the Chair of the Finance Committee. The Council meets at the Committee's biennial Scientific Assembly. Between Assemblies on a day-to-day basis COSPAR is run by the Bureau.

COSPAR President for the period 2014-2022 is Lennard A. Fisk (USA) and the Vice-Presidents are Karl-Heinz Glassmeier (Germany) and Mikhail Panasyuk (Russia). Members of the Bureau are: Catherine Cesarsky (France), Masaki Fujimoto (Japan), Manuel Grande (UK), Charles Kennel (USA), Pietro Ubertini (Italy) and Chi Wang (China).

The most recent 42nd COSPAR Assembly was held in Pasadena, California, USA, in July 2018. The 43rd COSPAR Assembly will take place in Sydney, Australia, 15-23 August 2020, and the 44th COSPAR Assembly will be in Athens, Greece, in 2022.

Following the success of the Capacity Building Workshop (CBW) on Crystallography for Space Science in April 2016 in 
Puebla, Mexico (http://www.inaoep.mx), a similar workshop/ school is proposed for Addis Ababa, Ethiopia, in 2021. Ethiopia is a new member of COSPAR (and does not belong to the IUCr), and organization of a workshop there creates a lot of challenges. Eyasu Leta is the CBW organizer and Yuki Kimura (IUCr) and Carlos Gabriel (COSPAR) will co-chair it.

In 2018 V. Shevtsova stepped down as a Chair of the Scientific Commission on Materials Science in Space (MSS Commission G). The new Chair is M. Avila (Germany) and Co-Chairs are T. Könemann (Germany), J. Porter (Spain) and T. Yano (Japan).

The official journal of COSPAR is Advances in Space Research (ASR), http://ees.elsevier.com/asr/, with an impact factor of 0.98 in 2018. ASR includes COSPAR's information bulletin Space Research Today. Another COSPAR journal, Life Sciences in Space Research, is a quarterly peer-reviewed scientific journal covering astrobiology, origins of life, habitability, life in extreme environments, effects of spaceflight on the human body, radiation risks and other aspects of life sciences relevant in space research.

In 2019 COSPAR organized three CBWs, covering a variety of new areas:

Principles and Practices of Nano-Satellite Engineering, 28 October - 1 November 2019, Tel-Aviv, Israel;

International Reference Ionosphere - Improving RealTime Ionospheric Modelling in the European and African Sector, 2-13 September 2019, Nicosia, Cyprus; and

Broadband Spectral and Timing Studies with AstroSat, Chandra and XMM-Newton, 9-20 March 2019, Mohali, Punjab, India.

In 2020 another four CBWs are being planned:

Pan-Ocean Remote Sensing Conference Tutorial, 15-19 September 2020, Johor Bahru, Malaysia;

Data Analysis for Planetary Sciences, 20-31 July 2020, Antofagasta, Chile;

COSPAR-INSPIRE Initiative on Small Satellites, 1 June 24 July 2020, Boulder, CO, USA; and

Coronal and Interplanetary Shocks: Analysis of Data from Space and Ground-Based Instruments, 6-17 January 2020, Kodaikanal, India.

The Panel on Capacity Building (PCB) Fellowship programme is open to young scientists who participated at one of the COSPAR CBWs, enabling them to build on skills gained at the workshop. It provides for visits of 2-6 weeks duration for the purpose of discussing ideas for a future workshop or carrying out joint research with one of the previously agreed lecturers/advisors of the corresponding workshop.

COSPAR co-organizes a limited number of meetings and colloquies each year that are of interest to its Associates. More information about this initiative can be found at https:// cosparhq.cnes.fr/events/co-sponsored-meetings.

In July 2019 Hanna Dabkowska stepped down as the IUCr Representative to COSPAR. Yuki Kimura accepted the honour of being the next IUCr Representative.

H. A. Dabkowska, IUCr Representative 2005-2019, and Yuki Kimura, IUCr Representative from 2019

\subsection{International Standards Organization (ISO)}

The Chair of the Commission on Crystallographic Nomenclature is a member of ISO.

There were no activities in 2019 related to crystallography. (The organization sends numerous e-mails but none of the subjects listed in those messages involved crystallography. As IUCr Representative, I $\log$ on to their website and read documents there from time to time to monitor their activities.)

Carolyn P. Brock, IUCr Representative

\subsection{International Organization for Crystal Growth (IOCG)}

The most important event concerning the IOCG (http:// www.iocg.org/) in 2019 was the official meeting of the organization, the 19th International Conference on Crystal Growth and Epitaxy ICCGE-19, 28 July - 2 August 2019, Keystone, Colorado, USA.

Twenty-four general sessions were organized. The conference was successful and well organized, even if the number of participants was lower than in the previous edition. The week before the conference, from 21-27 July, the 17th International Summer School on Crystal Growth ISSCG17 was held with about 100 students. Both the conference and the school were supported by the IUCr.

Many members and consultants of the Commission on Crystal Growth and Characterization of Materials (CCGCM) were involved in the organization of the conference and the school, but I would like to underline in particular the contribution of Thomas F. Kuech, Chair of ISSCG-17 and member of the CCGCM.

The IOCG conference is also the chance to consolidate the organization's Officers and Executive Committee.

Koichi Kakimoto (Japan, a consultant on the CCGCM) was confirmed as President. Co-Vice-Presidents are $\mathrm{H}$. Dabkowska (Canada) and E. Vlieg (NL), member of the CCGCM, the Secretary is S. Krukowski (Poland), and the Treasurer is J. Derby (USA). The members of the Executive Committee are Abel Moreno (Mexico), J. Y. Wang (China), both consultants on the CCGCM, Y. Mori (Japan), D. Maes (Belgium), A. Voloshin (Russia), C. Frank-Rotsch (Germany), J. De Yoreo (USA) and P. Muller (France).

The 20th ICCGE will be in Naples, Italy, in 2022, and will be co-chaired by A. Vecchione and A. Zappettini.

The IOCG looks very active in promoting crystal-growth conferences and schools. It should be mentioned that Eastern countries are gaining more and more interest in this field.

\section{A. Zappettini, IUCr Representative}

\subsection{International Centre for Diffraction Data (ICDD)}

The Commission on Powder Diffraction maintains close links with the ICDD, and has initiated discussions about how this relationship can possibly be developed into something more substantive and of mutual benefit.

D. G. Billing, IUCr Representative 


\subsection{Worldwide Protein Data Bank (wwPDB)}

The Protein Data Bank (PDB) has been a key resource for macromolecular crystallographers for almost 50 years, and its policies and development have been strongly influenced by the crystallographic community. Now known as the Worldwide PDB (wwPDB), it comprises four core entities, the RCSB$\mathrm{PDB}$ in the USA, PDBe in Europe, PDBj in Japan and the BMRB (NMR database). These are now being joined by the Electron Microscopy Database (EMDB), which will become a core partner in 2020 . The centres collaborate intimately and share the load, maintaining a single archive that is freely accessible to researchers, educators and students throughout the world.

The wwPDB was formally designated a Scientific Associate of the IUCr in 2015, and the IUCr provides a representative on the wwPDB Advisory Committee (wwPDB-AC). This committee also has representatives from the NMR and cryoEM communities, as well as regional representation, and is currently chaired by Dr Peter Rosenthal (UK). The 2019 meeting of the wwPDB-AC was held in Osaka, Japan, 17-18 October, and highlights of the year's activities are summarized below.

Some of the major issues from the past year are as follows:

The archive now comprises over 160000 macromolecular structures, which continue to grow in both size and complexity. About $90 \%$ of these have been determined by crystallography, but the number determined by cryo-EM is now increasing rapidly (1422 in 2019, compared with 9665 by crystallography). The annual increase in cryo-EM structures now far exceeds that for NMR (380 in 2019).

Important advances have been made in the validation of incoming structures. The validation of ligands (a long-standing need for crystal structures) has been markedly improved. Using BUSTER software, validation reports now provide geometrical validation and show ligands in their bias-removed electron density (ED). The ED map coefficients are also made available. Validation reports are now also provided for cryo-EM structures. These provide EM map validation and improved map/model validation is on the way.

A significant increase is taking place in the determination of hybrid structures, for example where parts of a structure have been determined by crystallography while other parts have been defined at lower resolution by small-angle scattering or other complementary techniques. A Hybrid Model Taskforce has been set up to develop protocols for representing such models appropriately in the PDB, and in the interim they are deposited in a developmental PDB-Dev database.

An important new initiative has come from China, which has pledged USD 3000000 per year for three years to establish a Chinese partner site (PDBc) for the wwPDB. This will be led by Drs Wenqing $\mathrm{Xu}$ and Zhijie Liu. The PDBc leadership has agreed to the wwPDB mission statement, detailed operational plans are being prepared, recruitment of staff is under way, and once this has been done load-balancing with the other wwPDB partners will be trialled. Establishment of an Indian partner site (PDBi) is proposed and has USD 600000 seed funding, but is at an earlier stage of development.

The change in format to mandatory use of mmCIF-based $\mathrm{PDBx} / \mathrm{mmCIF}$ files has been implemented during 2019 to better cope with the larger, more complex structures being determined and to better represent serial femtosecond crystallography (SFX) and XFEL data.

Depositors now have an option to improve or correct their earlier coordinate entries while retaining their original PDB identifier, thus retaining the link to publications. This will improve the data quality in older entries, and will be done by adding a version number. Validation reports are recalculated annually for all structures in the archive, giving depositors the opportunity to correct any problems identified.

The remediation of carbohydrate structures in the archive is continuing, to ensure that they conform to proper IUPAC/ IUBMB conventions of atom labelling and stereochemistry. In crystal structures, glycan chains on proteins are often poorly ordered and many archival entries violate stereochemical rules. Changes are only made with authors' consent, making remediation a slow process, but a much higher quality database is expected to be ready in 2020 .

Work continues to develop a Federated Databases model, in which structures in the PDB are linked to related data held in other databases. Relevant examples include the MX images databases that are currently being set up - under IUCr auspices - to archive the full sets of unprocessed diffraction images for particular structures, and the SASB database that is being developed, in an initiative led by Professor Jill Trewhella, for archiving biological SAXS data.

The PDB will reach its 50th anniversary (PDB50) in 2021, and plans are in place to celebrate this at meetings of the ACA (Indianapolis, May 2021), the ECM (Heidelberg, October 2021) and AsCA (Malaysia, December 2021).

The IUCr can be proud of the contribution made by the crystallographic community to this vital resource, and I am happy to be able to report that the relationship between the IUCr and the wwPDB is strong, and much appreciated by the wwPDB.

\section{E. N. Baker, IUCr Representative}

\section{Finances}

The Report and Financial Statements for 2019 are given as supporting information.

Transactions denominated in foreign currencies are translated into US dollars (USD) at the rates applying at the dates of the transactions. Monetary assets and liabilities denominated in foreign currencies at the balance-sheet date are retranslated at the rates applying at that date.

Investments are stated at market value. Changes in market value are taken through the income and expenditure account.

The accounts for 2019 presented in the supporting information have been produced using new accounting software (Xero). As part of the transition to the new software, some 
historical data had to be imported into Xero to track ongoing creditors, debtors etc. Some values brought forward from the 2018 accounts therefore differ slightly from those given in the accounts that were published as part of the Report of the Executive Committee for 2018. It is anticipated that the basic accounts will be easily retrievable from Xero in the future, with professional accountants only being required for the final stages of preparing the accounts and for the annual audit.

The balance sheet shows that the assets of the Union have increased during the year, from USD 3314039 to USD 3875 026. The movement in market value of the investments was a gain of USD 170654 in 2019 (compared with a reduction of USD 32769 in 2018).

The administrative expenses were USD 314791 in 2019, as compared with USD 304140 in 2018 (note that the 2018 figure given here excludes the costs associated with the IUCr website). Part of the increase was due to the cost of setting up Xero, but this should pay for itself in a reduction in professional accountancy fees and also ensure that the lower number of administrative staff employed during this triennium is sustainable.

The cost of the Finance Committee meetings held in 2019 was USD 20 260, while the Executive Committee meeting cost USD 46423 . These values are higher than those for 2018 owing to the higher overall travel costs for committee members to the USA than to Spain. The subscriptions from Adhering Bodies were USD 177 767. Interest on bank accounts and investments was USD 32679.
The journals for 2019 showed a surplus of USD 1038871 after journal-development costs were taken into account, as compared with a surplus of USD 974124 as calculated on a similar basis for 2018 .

The cost of the technical-editing office has been divided between the journals and International Tables for Crystallography in percentages based on the staff time spent on each publication. The technical-editing costs for the journals were USD 1149 447, as compared with USD 1223707 in 2018.

Books showed a deficit of USD 10 411, as compared with a small deficit of USD 80 in 2018. This is partly due to the costs associated with printing the new Volume $\mathrm{H}$ of International Tables for Crystallography and partly to an increase in the staff time allocated to International Tables to address an increase in workload. It is anticipated that sales of Volume $\mathrm{H}$ will counteract this deficit in 2020 . The net sales income for books was USD 118153 in 2019, as compared with USD 118336 in 2018.

The cost for the Union in producing the IUCr Newsletter in 2019 was USD 10 240, compared with USD 9915 in 2018.

USD 111772 was provided for financial support to young scientists, to enable them to attend scientific meetings sponsored by the Union. Visiting Professorships (USD 9837) and outreach and education costs (USD 83 035) in 2019 also contributed to the IUCr's good works.

An Outreach and Education Fund was established as part of the IYCr2014 legacy. In 2019 donations totalling USD 19942 were received. USD 1152 was also donated towards the IUCr's work in Africa. 